\title{
Un hito técnico sobresaliente: construcción del socavón de Nuestra Señora de Belén en la mina de mercurio de Huancavelica (Perú, 1606-1642)
}

\author{
Enrique Orche y María Pilar Amaré \\ Valencia 7, 36203 Vigo. \\ eorche@gmail.com,atpilar@yahoo.com
}

\begin{abstract}
RESUMEN
El presente trabajo describe la génesis y construcción del socavón Nuestra Señora de Belén, que permitió seguir explotando la mina de Huancavelica desde 1642 hasta el final del periodo colonial. Se trata de una larga galería (520 m), de gran sección (3×3 m), cuya construcción no ha sido abordada por la historiografía minera, excepto algunos episodios concretos. Para su estudio se han consultado, entre otras fuentes, documentos originales de los propios protagonistas de la época que, paso a paso, describieron tanto la necesidad de la obra como su desarrollo durante los años que duró. En la etapa final de su construcción se empleó por primera vez en América la pólvora como explosivo en galería; también se introdujo una modificación importante en la organización laboral de la obra consistente en sustituir el modelo público por la contratación privada, lo que mejoró sustancialmente los avances. La galería caló la mina tras haber sido redirigida varias veces en los controles técnicos efectuados sobre ella.
\end{abstract}

Palabras clave: Huancavelica, mercurio, mina, mineral, yacimiento mineral.

\section{An outstanding technical milestone: construction of the Nuestra Señora de Belén adit in the mercury mine of Huancavelica (Peru, 1606-1642)}

\begin{abstract}
This paper describes the genesis and construction of the Nuestra Señora de Belén adit which allowed the Huancavelica mine to continue to be exploited from 1642 until the end of the colonial period. It is a long gallery (520 m), with a large section $(3 \times 3 \mathrm{~m})$, and its construction has not previously been published in full except for some specific episodes. Amongst other sources, original documents from the protagonists themselves have been consulted in order to describe it step by step, including both the need for the work and its development during the years it lasted. In the final stage of its construction, gunpowder was used as a gallery explosive for the first time in America; an important modification was also introduced in the organization of labour which consisted of changing from the public model to the hiring of a private one, which substantially improved progress. The gallery penetrated the mine after having been redirected several times by the technical controls carried out on it.
\end{abstract}

Keywords: deposit, Huancavelica, mercury, mine, ore. 


\section{Introducción}

La mina de azogue de Huancavelica fue denominada Joya de la Corona debido a la gran importancia que dicho metal tuvo en la obtención de oro y plata por amalgamación en el virreinato del Perú. Las principales minas que utilizaron el mercurio de Huancavelica fueron Potosí, Porco, Oruro y otras, aunque también se llevó en pequeñas cantidades a Méjico. Mantener la mina en producción fue una tarea que los sucesivos virreyes tuvieron que acometer por encargo expreso de la Corona, debido a la gran importancia que tenía la plata en la economía española. Por ello, la explotación de la mina de Huancavelica pronto se hizo imprescindible, salvo que, como alternativa, se importara mercurio desde Almadén o Idria. Dicha explotación fue progresando en profundidad pero, al tener que introducir métodos de laboreo subterráneo, comenzaron los problemas. La codicia de una buena parte de los mineros y de las autoridades, arrancando mineral rico de los pilares y de otros elementos de sustentación, condujeron a situaciones límite que provocaron derrumbes, cortes de accesos, falta de ventilación y una alta siniestralidad de los obreros. Llegado un determinado momento, la situación se hizo tan insostenible que las autoridades pergeñaron un plan para resolver, al menos, los problemas del acceso y de la ventilación. A tal fin promovieron la construcción de tres labores muy diferentes con el objetivo común de alcanzar los trabajos subterráneos profundos que había sido preciso abandonar y donde, precisamente, estaba el mineral rico. La primera de estas labores fue un gran desmonte a cielo abierto, la segunda unas lumbreras verticales y la tercera un largo socavón horizontal. Las tres se comenzaron, pero la que finalmente se llevó a cabo en su totalidad y resolvió el problema, fue esta última.

El presente artículo explica y relata por primera vez los hechos completos secuenciados en el tiempo. El objetivo del mismo es comprender como se construyó el socavón Nuestra Señora de Belén y dar a conocer tan importante obra de la ingeniería de minas hispana. Dada la complejidad de la obra, muchos fueron los aspectos colaterales que influyeron en ella. De todos ellos se trata en relación con el avance del socavón en cada momento pues el hilo conductor es la historia de la propia mina y eso no se puede obviar.

La metodología de la presente investigación se ha basado en la consulta exhaustiva de los fondos documentales del Archivo de Indias y de la Biblioteca Nacional de España.

\section{Justificación de la construcción del socavón}

Es bien conocido el papel del mercurio en el beneficio por amalgamación de los minerales de plata. En América, la mina de Huancavelica, registrada por Amador de Cabrera en Huamanga el 1 de enero de 1564 , fue la principal fuente del azogue. Tras este hecho, en muy breve espacio de tiempo se denunciaron y otorgaron multitud de concesiones mineras que, inmediatamente, comenzaron a trabajarse simultáneamente en diversos lugares del criadero.

En realidad, la denominada mina de Huancavelica o de Santa Bárbara se refería inicialmente a diversas minas (denuncios) que tuvieron el objetivo común de explotar el mercurio del yacimiento próximo a la villa homónima. Éste constituye el cuarto yacimiento más importante del mundo, detrás de Almadén (España), Idria (Eslovenia) y Monte Amiata (Italia).

Al principio de su explotación, el mercurio que se obtenía se podía vender libremente con la única condición de entregar a la Corona el quinto en las minas de piedra y el octavo en los yacimientos llamados de lavadero (antiguas escombreras o restos de origen incaico). Pero pronto, la Corona quiso controlar estas minas tan importantes para la producción de plata, lo que provocó conflictos prolongados en el tiempo que, en numerosas ocasiones enfrentaron a los virreyes con los mineros.

La mano de obra debía ser, necesariamente, indígena pues los esclavos negros, debido a la rigidez del clima huancavelicano, perecían en cuanto se aplicaban a trabajos sostenidos, y los trabajadores españoles, dado su escaso número, tampoco eran alternativa. Tras contemplar distintas posibilidades y considerando las negativas actitudes y experiencias laborales libres habidas con los nativos, el virrey Francisco de Toledo consultó con importantes asesores laicos y eclesiásticas que decidieron que los nativos podían ser compelidos a prestar servicios en las minas (Lohmann, 1949; Sala, 1994). De esta forma, el 20 de enero de 1571 el virrey firmaba las ordenanzas sobre el beneficio de las minas de Huamanga y Huancavelica y el régimen laboral de los indígenas (Toledo, 1986). Posteriormente, el 14 de noviembre del mismo año, el Consejo de Indias consideraba que la Corona era la propietaria de las minas y, poco más de un año después, el 16 de febrero de 1573, Gabriel Loarte, comisionado por el virrey, incautaba las 43 minas que había en ese momento. La mina Descubridora de Amador de Cabrera fue la única que el concesionario pudo retener. A partir de dicha incautación, el Estado instauró una suerte de contrato legal con los mineros, denominado asiento, de duración limitada aunque prorrogable, en el que se señalaba a los distintos aspectos a 
cumplir, entre ellos la producción y el precio del metal, tasados, el número de indios de mita asignados al trabajo y la obligatoriedad de entregar toda la producción de mercurio a la Corona. Sin embargo, las autoridades modificaban continuamente las condiciones e incumplían con frecuencia sus compromisos económicos en lo relativo a adelantos y abono de las entregas (Amaré y Orche, 2019).

Las concesiones iniciales en el cerro Santa Bárbara que, en los años posteriores, serían de mayor importancia se indican en la Figura 1. El documento original de 1605 contiene una breve e imprecisa descripción de las labores mineras ejecutadas en ellas hasta dicho año. En la figura se han destacado los nombres de las concesiones (minas). Con el tiempo, posiblemente como consecuencia de la expropiación general en la que perdieron su identidad individual como entes en explotación, las minas en su conjunto se denominaron genéricamente con el nombre de Santa Bárba$\mathrm{ra}$, patrona de los mineros, por la que se sentía y se siente gran devoción en las minas de España y, sobre todo, de Europa central. Todas las minas indicadas tenían unas dimensiones de $30 \times 60$ varas $(25 \times 50 \mathrm{~m})$ excepto la Descubridora, también Ilamada Todos los Santos, de Amador de Cabrera, que era de 40x80 varas $(33 \times 67 \mathrm{~m})$. En el dibujo original se indica la posición de la boca del socavón que, en 1605, permitía acceder a las labores subterráneas de las minas San Jacinto, Nueva, Inés de Robles, Juan García, Correa de Silva y El Charco. También se indica el punto donde, años después, se previó que llegara el socavón de Nuestra Señora de Belén.

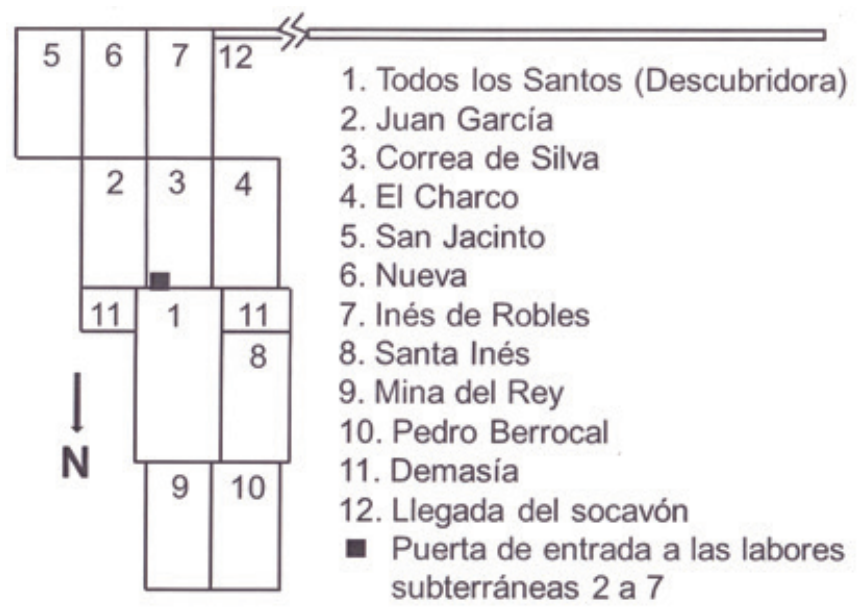

Figura 1. Concesiones mineras primitivas en el cerro Santa Bárbara (Fuente: Autores basada en AGI. MP-PERÚ_CHILE, 4).

Figure 1. Primitive mining concessions in the Santa Bárbara hill (Source: Authors based on AGI. MP-PERÚ_CHILE, 4).
Una vez regulado el sistema laboral mediante la mita, las minas entraron en un periodo de actividad en el que llegaron a producir hasta 11.000 quintales anuales de azogue. La explotación comenzó siendo a cielo abierto pero en 1597, cuando profundizó la veta, se cambió al método subterráneo abriéndose un socavón que comenzaba a $50 \mathrm{~m}$ de profundidad y debía penetrar $100 \mathrm{~m}$ en roca para poder llegar a los tajos en explotación (Sala, 1994). Era una galería profunda y tortuosa a la que se accedía mediante pasillos y escalas provistas de travesaños sólidos y anchos. Nadie se había ocupado de prever las necesidades de aire limpio que el trabajo demandaba, ni construyendo lumbreras ni procurando tiros de ventilación. Los efectos del cambio de laboreo sobre la salud de los trabajadores fueron inmediatos y graves, siendo denunciados los daños que padecían por todos los estamentos de la sociedad colonial. El polvo del mineral arrancado, el azufre y el humo de las velas contaminaban el aire ocasionando daños que en la época no se sabía cómo tratar y que, muchas veces, tenían como consecuencia la muerte.

EI 5 de mayo de 1600, el virrey Luis de Velasco requería a la Corona una solución al problema haciéndole ver la incidencia del mismo en la producción de plata. La Corona no contestó por lo que Velasco repitió su petición un año después. No obstante, las autoridades estaban prestando atención al asunto redactando discretamente una cédula sobre el trabajo de los indígenas que tendría gran trascendencia en la vida colonial. Dicha norma, emitida el 24 de noviembre de 1601, no era de fácil cumplimiento en Huancavelica ya que propugnaba para los indios el estatus de trabajadores libremente asalariados que, además, debían laborar en condiciones tolerables de trabajo. Rápidamente, el virrey informó a Madrid de que en Huancavelica nadie se presentaba voluntariamente a trabajar debido a la hondura de la mina, al riguroso clima y a la gran distancia a los pueblos en los que vivían, incluso a pesar de que para hacer frente a las enfermedades adquiridas en el trabajo minero, se creó un hospital subvencionado por la Real Hacienda colocando un médico al frente del mismo (Sala, 1994).

A principios de 1604 el virrey solicitó dictámenes técnicos a dos expertos, Francisco Tofiño y Hernán González, que confirmaron el pésimo ambiente de las labores y el daño sufrido por los operarios. Oyó también el virrey la opinión del Protector de Naturales, asimismo muy crítico con las condiciones de trabajo, que juzgó muy peligrosas por lo que abogó por la mejora urgente de las mismas, incluso a costa de la menor cantidad de azogue extraída, ya que la muerte de los indios llevaría a la paralización de la producción de mercurio y, con ella, de la plata. El virrey Velasco tomó nota y el 4 de febrero presentó la situación en 
el Acuerdo de Hacienda que, unánimemente, acordó prohibir totalmente los trabajos en el socavón, que inmediatamente se tapió, trasladando los trabajos a otros sectores de la mina que se podían explotar a cielo abierto. Lamentablemente el mineral que se benefició pasó a ser el remanente ubicado en superficie, de ley tan baja que apenas cubría los gastos de extraerlo. La consecuencia inmediata fue un radical descenso de la producción de mercurio que era obtenida de un desmonte que fue adquiriendo forma de gran zanjón (Lohmann, 1949; Sala, 1994).

En 1604 perduraban las dudas del virrey sobre la manera de aplicar la cédula de 1601 pero, en dicho año, fue relevado de su cargo siendo sustituido por Gaspar de Zúñiga Acevedo y Velasco, conde de Monterrey, que había recibido instrucciones precisas para aumentar la producción de mercurio. Apenas llegado al Perú, con objeto de informarse de primera mano sobre la situación en la mina de Huancavelica, nombró visitador al militar Pedro Ozores de Ulloa, que tenía experiencia en la gestión de las minas de Potosí por haber sido corregidor de dicha villa. El virrey recabó también la opinión de diversos mineros y preparó una Junta para tratar el asunto. Previamente había tomado varias medidas como elevar a Huancavelica y su distrito a la categoría de gobernación, independizándola de Huamanga; de esta forma se colocaba la explotación bajo la autoridad directa del virrey y de la Audiencia de Lima. Además, designó un oidor responsable de su gobierno, nombramiento que recayó en Fernando Arias de Ugarte, persona que se había distinguido por su laxa opinión sobre el cumplimiento de la cédula de 1601. Con estas medidas se pusieron las bases para retomar el trabajo de explotación con mayor rendimiento, esto es, por minería subterránea aunque, esta vez, con auxilio de la técnica (Sala, 1994).

Durante la celebración de la mencionada Junta, tanto el visitador Ozores de Ulloa como el gobernador Arias de Ugarte consideraron que había que mejorar la ventilación interior de las minas aunque con distinto criterio. El primero proponía realizar un socavón (posteriormente llamado Nuestra Señora de Belén) que alcanzase las labores más profundas, concretamente las de las minas Nueva, Inés de Robles y San Jacinto, mientras que el segundo prefería perforar dos lumbreras o galerías de ventilación verticales. Esta disparidad de criterios causó una profunda rivalidad y distanciamiento entre Ozores y Arias que duraría hasta 1608 (Sala, 1994).

Cuando el virrey conde de Monterrey llegó a Lima el 8 de diciembre de 1604, enseguida tuvo que recibir a los mineros que se quejaron de la prohibición del virrey Velasco de mantener la explotación subterránea del cerro Santa Bárbara, cuya mejor demostración era el escaso rendimiento obtenido en la mina en ese año mediante el zanjón a cielo abierto. Para informarse de primera mano, el 1 de marzo de 1605 el virrey encargó a Ozores la realización de una visita durante la cual, entre otras cosas, debía comprobar si continuar con la apertura del zanjón era el método adecuado de beneficiar el yacimiento. También debía estudiar la conveniencia de perforar unas lumbreras a fin de que se airearan las labores subterráneas profundas y se pudiera reanudar el trabajo en ellas sin necesidad de descender por escalas (AGI. Patronato, 239, R. 41, F. 2r-3v; Lohmann, 1949). Ozores se dirigió inmediatamente a Huancavelica donde recurrió a doce expertos en minería, entre ellos el agrimensor Francisco Tofiño que ya había visitado las minas con anterioridad, Diego López, conocedor de la mina de Almadén, y varios funcionarios de Hacienda. Ozores no pudo visitar las labores debido a una grave dolencia reumática pero los técnicos que le acompañaron tantearon el rumbo de las vetas y efectuaron cálculos para evaluar las medidas a tomar mientras que Ozores emitió un auto para recabar la opinión de expertos. En concreto se proponía conocer:

[...] si para mayor perpetuidad de las dichas minas, buena y segura labor, y para la mayor salud y menos trabajo de los indios que en ellas se ocupan, convendría dar pozos y lumbreras a pique al metal virgen de las dichas minas y para respiradero de aire y otros servicios de ellas, y socavón o socavones que las atraviesen y tomen, $y$ en qué partes se pueden dar conforme a lo que han visto, y si se mandare hacer por su Excelencia, qué indios será bien se ocupen en cada uno de los pozos, lumbreras y socavones, y qué coste tendrá cada año (AGI. Patronato, R. 38, F. 33r-33v).

Ante Ozores declararon buen número de personas, más o menos expertas, más o menos comunicativas, que coincidieron en lo principal de sus opiniones y eran favorables a las obras propuestas. En lo que respecta específicamente al socavón posteriormente denominado Nuestra Señora de Belén, el Protector de Naturales y antiguo veedor de las minas Francisco Romero Mudarra creía que, si no era a costa de la Real Hacienda, no se podrían hacer ni el socavón ni los pozos, y que para construir la galería se podrían repartir de 60 a 70 indios para que trabajasen en ella día y noche por turnos, estimando que el coste anual de la labor sería de diez a doce mil pesos (AGI. Patronato, 239, R. 38, F. 35v).

Por su parte, el minero Juan Tomás opinaba que el socavón era muy necesario para garantizar el futuro de la mina: debía abrirse en la quebrada de La Trinidad, ser trabajado por 70 u 80 indios y ser abonados por Su Majestad los once a doce mil pesos anuales que costaría (AGI. Patronato, 239, R.38, F. 36v). 
Consultado también Jorge Fonseca, minero experto conocido por sus informes, afirmó que los pozos, lumbreras y socavones serían muy útiles, y que si el socavón no se realizaba antes de muy pocos años, no habría seguridad de que la mina pudiera seguir produciendo mercurio ni los indios trabajando en ella en condiciones saludables. En su opinión deberían dedicarse 60 o 70 indios a la excavación del socavón que trabajarían en él de noche y de día. El coste anual de la labor sería de once o doce mil pesos dedicados a la paga de españoles, indios y barretas (AGI. Patronato, 239, R.38, F. 37v-38r).

El experimentado minero Pedro de Vascones insistía en razones similares a las anteriormente citadas aunque incidía en la absoluta necesidad de abrir el socavón pues, de no hacerse, ni la mina ni la producción de azogue tendrían continuidad (AGI. Patronato, 239, R.38, F.39r-39v).

Ozores recogió estas y muchas otras opiniones similares en un detallado informe fechado el 9 de abril de 1605 (AGI. Patronato, 239, R.41, F. 10v-18r). En el mismo sostenía que debía seguirse con la excavación del zanjón a cielo abierto pero, para sacar los $100 \mathrm{~m}$ de material que restaban hasta alcanzar las labores subterráneas antiguas en un plazo de tiempo razonable, sería necesario aumentar significativamente el número de operarios, cuya labor debería centrarse en alcanzar las labores subterráneas de las minas Correa de Silva y Juan García para extraer los pilares y macizos de mineral dejados en ellas como apoyos. De seguirse sus indicaciones se podría llegar a estas minas en un año. No obstante Ozores se decantaba por la perforación de un largo socavón, como se hacía en Potosí, abierto en la quebrada de LaTrinidad, para llegar a las labores subterráneas de las minas Inés de Robles, Nueva y San Jacinto (AGI. Patronato, 239, R.41, F.13r).

La primera descripción del socavón la ofreció Ozores en el citado informe de 9 de abril de 1605. El proyecto original de la galería data de mayo de 1605 (AGl. Lima, 35). Por su interés se reseñan los aspectos más importantes del socavón y sus efectos (Figura 2).

(El socavón) se rumbeó y ha de correr franco del este al oeste, y habiendo hecho primera y segunda vez las medidas, parece tiene 753 varas de longitud, con lo que se tomó para él pendiente que ha de tener y para la entrada, y según lo que se pudo ver por la haz de la tierra, que parece providencia divina a nuestra facilidad en darle porque muestra ser sencilla, sin que en todo lo que ha de correr haya farallones ni cantería, excepto las crestas que tienen las minas que llaman de La Trinidad, que serán a lo que se ve y puede colegirse, de 8 estados de ancho. $Y$ esto por el centro ha sido metales ricos que se labraron en tiempo de los incas $y$, algunas veces, en éste, $y$ se han dejado por estar mal reparadas y por acudir a la riqueza principal. Y según la cuenta y razón, dándose el socavón tomará estas minas en 70 estados de profundidad con que se debe creer que hasta este paraje llegue la cantería o las cajas de las vetas que por allí corrieren, [...] y serán de mucho provecho por la riqueza que en ellas se puede sacar y por la correspondencia que con más facilidad se hará de las labores antiguas y al respiradero de aire, y no se debe temer agua que estorbe la prosecución de este socavón porque en todas aqueIlas vertientes no las hay en manantial ni laguna por la haz de la tierra. Y por lo que muestra, se entiende que corriendo 20 estados la labor de él, se dará en tierra enjuta por la pendiente que lleva la ladera. El cuál (socavón) ha de tener 3 varas de alto en bóveda y 3,5 de ancho, con que será capaz para entrar y salir todo número de gente que labrare las minas sin estorbo ninguno, aunque salgan y entren con carretoncillos como por otro socavón semejante se sabe se hace hoy día en las minas de Almadén. Y cuando los indios vayan y vuelvan por él cargados, no vendrán a tener de diez partes una del trabajo que hoy pasan.

La facilidad y provecho que esto tiene muestra con evidencia clara el cerro de Potosí en 12 socavones que de esta misma suerte están dados en él por particulares que le acudían. [...].

La costa que tiene el socavón tendrá cada año y los indios que se deben ocupar en él, aunque los mineros lo declaran en información particular que sobre esto y otras cosas se hizo, me ha parecido no dejar de decirlo para cumplir en todo con el mandato de Vuestra Excelencia. Los indios serán bastantes 60, con los cuales han de asistir forzosamente dos españoles, que en su salario y en el jornal de los indios y en barretas, picos y otros adherentes, hecha la cuenta por lo más limitado llega a 11.000 patacones (pesos corrientes) cada año, con consideración que la mitad de los indios han de trabajar de día y la otra mitad de noche, que para ellos es tan fácil lo uno como lo otro, y no habiendo cosa de las que no se puedan prevenir y que lo estorbe, tengo por cierto se acabará el socavón en

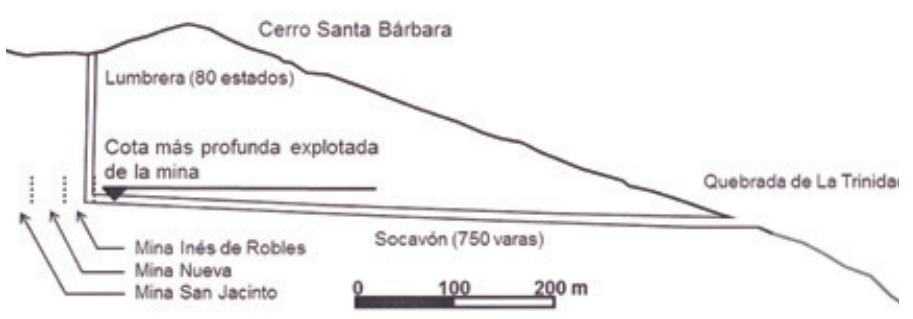

Figura 2. Perfil del socavón propuesto por Pedro Ozores (Fuente: Autores basada en AGI. MP-PERÚ_CHILE, 5).

Figure 2. Profile of the adit proposed by Pedro Ozores (Source: Authors based on AGI. MP-PERÚ_CHILE, 5). 
menos de 4 años, y cuando sea algo más, como es posible ser menos, no vendrá a tardar para labrarse por él las minas prohibidas pues para este tiempo, y aún para más, había bastante azogue en los pilares, puentes, barrigas y tablones de las minas Correa de Silva y Juan García (AGI. Patronato, 239, R. 41, F. 12v-18v).

Esta era la primera propuesta para perforar el socavón de Nuestra Señora de Belén. Puesto que estas labores debían realizarse en el contexto del asiento firmado con los mineros, al igual que se estaba haciendo con la excavación de los desmontes del zanjón, el 21 de junio de 1605 se suscribió un protocolo adicional al citado convenio que, entre otras cuestiones, aumentaba el número de provincias sometidas a la mita con lo que se podrían reforzar los trabajos en el desmonte.

Por estas mismas fechas, y deseando tener un segundo punto de vista, el 27 de junio de 1605 el virrey encargó al gobernador Arias que se informase detenidamente sobre distintos aspectos de la minería huancavelicana, entre ellos, de la conveniencia de construir el socavón propuesto por Ozores (BNE. Ms. 3.041, F. 403r-407v).

Arias llegó a Huancavelica el 19 de julio e inmediatamente ordenó al agrimensor Tofiño que reconociera el terreno. No pudieron descender a las galerías por haber desaparecido las escaleras pero si visitar los terrenos en superficie. Vista la situación en ellos, Arias se percató de la imposibilidad de seguir explotando a cielo abierto debido a la enormidad de desmontes que había que retirar, y que la única posibilidad de llegar al mineral era mediante lumbreras y socavones. Los problemas para acceder al mineral mediante el zanjón eran muchos: el agua de lluvia que se acumulaba en el terreno, la climatología, la cantidad de roca estéril que era preciso extraer para abrir el enorme hueco necesario y la escasez de personal, hasta el punto de que Arias estimó que al ritmo de trabajo que se llevaba en aquellos momentos, se tardarían más de 20 años en llegar a las antiguas minas subterráneas. Además, no se estaba descubriendo mineral remunerativo, lo que amenazaba con destruir el entramado metalúrgico de Huancavelica.

Las propuestas que se habían planteado para solucionar el problema de la ventilación y del acceso al mineral rico se resumen en la Figura 3. Se trata de un perfil esquemático transversal al farallón o veta principal, que no está a escala y es puramente conceptual. En él se aprecia la enormidad del desmonte que se proponía realizar. Las alternativas eran seguir profundizando el citado desmonte excavando más de $100 \mathrm{~m}$ de roca virgen, o construir un socavón o unas lumbreras hasta que cortaran las labores subterráneas.

Ninguna de las tres soluciones planteadas era fácil: el desmonte implicaba un gran movimiento de tierra por medios manuales, con mineral de baja ley en el farallón y estéril en los taludes laterales que debían realizarse para estabilizar el hueco; por otra parte, acometer las lumbreras y el socavón implicaba realizar obras importantes para la época, tanto por sus dimensiones como por su dificultad intrínseca. En todos los casos habría que excavar materiales de naturaleza muy diversa, desde los muy duros a los altamente inestables que habría que sostener con muros de piedra o entibaciones de madera (ademes).

Arias trasladó sus razones al virrey, convenciéndole de que el cielo abierto, tal como estaba enfocado, no era la solución por lo que el conde de Monterrey encargó al gobernador una información que recogiera las opiniones de los mineros y otras personas expertas y definiera una solución concreta y aceptable entre el desmonte, las lumbreras y el socavón. Una primera consulta tuvo lugar en agosto; concretamente, el día 25 se requería la opinión del prestigioso minero Juan de Sotomayor que, respecto del socavón de Nuestra Señora de Belén, dijo que, habiéndose de dar, el mejor lugar para emboquillarlo era donde lo había señalado Pedro Ozores de Ulloa, en la vertiente de la mina LaTrinidad. Sin embargo, Sotomayor opinaba que no convenía dividir las fuerzas en las tres labores posibles sino proseguir con los desmontes y dar las lumbreras (AGI. Patronato, 239, R. 43, F. 74r).

El testimonio de Sotomayor confirma que no creía demasiado en la viabilidad del socavón, posiblemente por su magnitud y coste. Tres días después, el 28 de agosto, declaró Lorenzo Martínez, veedor de Huancavelica que, mucho más explícito que Sotomayor, opinaba muy favorablemente sobre el socavón, el cual debía llegar hasta las zonas vírgenes de la mina San Jacinto, permitiendo un trabajo más descansado a los indios apiris (cargadores) pudiendo llegarse, incluso, a sacar el mineral y, si los hubiere, los desmontes y

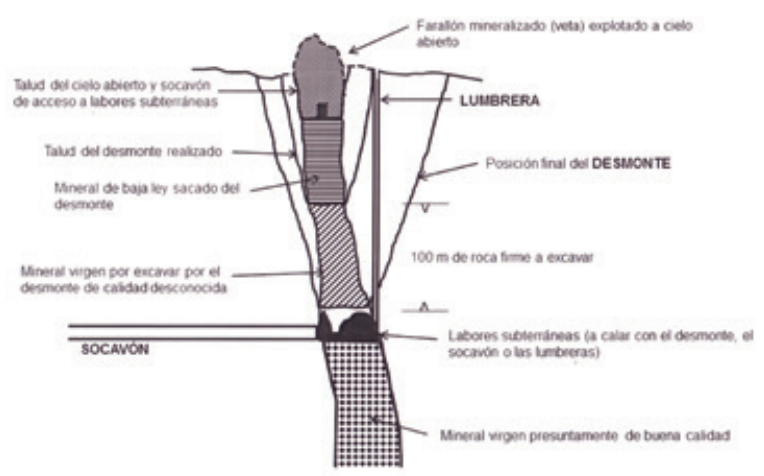

Figura 3. Esquema de situación y soluciones (Fuente: Autores). Figure 3. Diagram of the situation and solutions (Source: Authors). 
lodos finos, en carretones. Asimismo el socavón evacuaría el agua, daría suficiente ventilación, sería una vía de entrada y salida al interior de la mina y podría descubrir nuevas vetas. En su opinión, estaría concluido en siete años si trabajasen 24 indios de forma continua durante las 24 horas del día, aunque este plazo podría verse afectado por los acontecimientos o imprevistos que pudieran ocurrir en el futuro (AGI. Patronato, 239, R. 43, BI. 6, F. 79v).

Un tercer testigo, el experto minero Rodrigo de Torres de Navarra, declaró el 3 de septiembre de forma escueta y pragmática su temor sobre la magnitud de la obra del socavón que consideró muy larga y de muchas dificultades por la gran distancia que había que salvar (AGI. Patronato, 239, R. 43, BI. 6, F. 74r).

En octubre de 1605, Arias realizó otra encuesta más exhaustiva que la anterior (AGI. Patronato, 239, R. 43, Bl. 6). Para completarla se volvió a requerir su opinión a las mismas personas que en abril informaron a Ozores las cuales, tras haber trabajado cuatro meses en el desmonte a cielo abierto propuesto, consideraban conveniente que solo se excavara hasta llegar a las labores de la mina Juan García, donde comenzaba una roca viva que era imposible de atravesar, hasta el extremo de que ni un millar de operarios, trabajando diez años, podrían vencer su dureza. Con dicha mina abierta al exterior por el desmonte, se podría emplear el hueco para ventilar las restantes. Por otra parte, la opinión del minero Juan de Sotomayor sobre la propuesta de realizar el socavón de Nuestra Señora de Belén, insistía en que la longitud prevista de la obra, de más de 700 varas $(585 \mathrm{~m})$, alargaría mucho su ejecución, y más teniendo en cuenta que los afloramientos de rocas duras que se veían en superficie posiblemente serían cortados por el socavón en profundidad; además, consideraba que, dada la sección de la galería, sólo podrían trabajar en ella unos pocos operarios por falta material de espacio, y que no trabajarían con la intensidad que lo hacían en la mina de la que sacaban provecho personal. Sin embargo, siendo la producción de mercurio tan necesaria para la Hacienda Real y el bien general, por pura necesidad pedía que tanto las lumbreras como los socavones y los demás remedios que se propusieren, se pusieran en ejecución sin reparar en gastos con objeto de que se pudiera emplear el que antes se terminase o fuese más conveniente (AGI. Patronato, 239, R. 43, Bl. 6, F. 23r-23v).

En el informe que resultó de estas nuevas consultas, que tiene fecha 3 de noviembre de 1605, Arias planteó, además de la suspensión de los trabajos a cielo abierto en los desmontes, la perforación de dos lumbreras verticales, una en la mina Nueva, junto a las estacas de la de San Jacinto, y otra entre las minas Nueva e Inés de Castro sin que por ello se descartase el socavón previsto debido a la gran utilidad que tendría cuando fuera concluido, si bien la obra sería más larga y, al parecer, de mayores dificultades (AGI. Patronato, 239, R. 43, BI. 6, F. 89r). Las medidas propuestas por Arias fueron aprobadas por acuerdo de la Junta de Hacienda de 20 de noviembre de 1605, incluida la realización del socavón de Nuestra Señora de Belén.

\section{Primeros pasos del socavón de Nuestra Señora de Belén}

Mediante auto de 31 de diciembre de 1605 Arias de Ugarte ordenó abrir el socavón que, en dicho documento, fue bautizado como Nuestra Señora de Belén (Lohmann, 1949). La obra se inició a principios de 1606 pues en carta a la Audiencia de 22 de mayo de este año informaba que había hecho comenzar la galería en una peña por asegurar la entrada, ya que el terreno del cerro en aquella parte era tan poco resistente que se desmoronaba por la acción del agua y del sol. Sin embargo, reconocía que la roca era tan dura que aunque muchos días no se pudo avanzar, se había ablandado y se podía excavar (AGI. Patronato, 239, R. 43, BI. 1, F. 1r-1v).

Tofiño dirigió las labores, con Cristóbal de Fonseca como sobrestante. Desde agosto de 1606 colaboró también voluntariamente Manuel Fraile, experto minero con largos años de trabajo en las minas de Zaruma, en el actual Ecuador (Lohmann, 1949). Precisamente durante este mes se señaló el rumbo del socavón que sería al este cuarta al nordeste (AGI. Lima, 94).

Tiempo después, el 5 de febrero de 1608, Ozores de Ulloa dejaría por escrito al virrey su disconformidad con el sitio y manera de abrir el socavón por diferente lugar del que había propuesto él, en terreno blando, debido a que los mineros certificaron que la galería no podría excavarse si no iba por roca sólida. Por ello, consideró errada la obra, que se tardaría en acabar muchísimo tiempo, más de 30 años en lugar de los 5 o 6 previstos (BNE. Ms. 3041, F.154r-154v, 157v).

Cuando se iniciaron las obras del socavón, las lumbreras y el desmonte, los mineros asentistas protestaron al conde de Monterrey porque no podían sacar el azogue comprometido en el asiento vigente debido a la mala calidad de las zonas que les habían asignado para explotar y, además, estaban costeando los salarios de los indios que participaban en las tres obras citadas. Como todo ello estaba controlado por Arias, para vigilar los resultados de las obras acometidas por éste, el virrey nombró gobernador de Castrovirreyna a su protegido Ozores de Ulloa, el cual debía reconocer in situ la situación de las minas huancavelicanas durante el viaje de vuelta que emprendería desde Lima a dicha ciudad, pues Huancavelica estaba ubicada en el camino que llevaba a ella (Lohmann, 1949). 
En el día a día de las obras, Arias advirtió que la apertura del socavón había presentado dificultades desde el principio y las seguiría presentando a lo largo de su construcción, lo que comunicó al virrey. En ese momento el socavón había avanzado 14 varas $(12 \mathrm{~m})$ en rocas muy duras, y se había desviado notablemente del rumbo previsto. Arias comentaba al virrey que en Huancavelica y su comarca no había nadie que supiera dirigir este tipo de obra por lo que solicitaba que se enviasen de Almadén o de Alemania expertos para este cometido y, también, para conducir la labor de las minas y la producción de azogue (AGI. Lima, 94).

Por su parte, el conde de Monterrey mantenía informada a la Corona de la situación de las minas huancavelicanas, incluida la solicitud de expertos en minería hecha por Arias, mediante cartas del 16 de mayo, 3 de noviembre y 14 de diciembre de 1605 . Lamentablemente, el 10 de febrero de 1606 fallecía el virrey, y no recibiría la cédula del 28 de junio de 1606 mediante la cual la Corona contestaba a sus peticiones. En ella se agradecía la prolija información remitida y se aprobaba la construcción del socavón propuesto por Ozores que se consideraba obra de la mayor utilidad, mientras que la construcción de las lumbreras presentaba muchas dificultades. La Corona ordenaba que se buscasen expertos en minería en España o en Alemania para que viajasen al Perú con la mayor brevedad y mandaba que se procurase abrir el socavón y que se mantuviera el trabajo en las minas con toda diligencia para que no faltase azogue (BNE. Ms. 2969, F. 311).

El socavón, por tanto, ya contaba con la autorización real pero su perforación no debía interferir con la producción de mercurio. Entretanto, en Perú, fallecido el virrey, la Audiencia consideró oportuno llamar a Arias para que informase de la situación en Huancavelica y, además, como oidor que era, colaborara con los demás magistrados en la administración interna del virreinato.

Mientras Arias llegaba a Lima, el secretario de la Audiencia, asumiendo el rol del virrey fallecido, atendió la petición de Arias y escribió a la Corona una carta en la que solicitaba se le enviase una relación detallada de cómo se explotaban las minas de Almadén $y$, sobre todo, insistía en que se enviasen expertos en minería (AGI. Lima, 94).

Por su parte, Arias, antes de abandonar Huancavelica, a petición de la Audiencia, dejó escritas instrucciones precisas al corregidor, oficiales reales, veedores, demás ministros y mineros para que continuaran las labores emprendidas, y preparó una información llamando a varios testigos. Mediante declaraciones tomadas entre el 6 y 7 de diciembre de 1606 informaron a Arias de que el socavón tenía una longitud de 22 varas y una ochava $(18 \mathrm{~m}), 3$ varas $(2,5 \mathrm{~m})$ de alto $y$ otras tantas de ancho, y que se había construido, entre otras, la casa de dos piezas en la que ya vivía Cristóbal de Fonseca, sobrestante del socavón, aunque todavía le faltaban puertas y ventanas (AGI. Patronato, 239, R. 43, BI. 8, F. 2r-8r). Entre las instrucciones redactadas el 9 de diciembre para que se continuaran los trabajos durante su ausencia, Arias mandaba, respecto del socavón, que el veedor encargado pusiera especial cuidado y diligencia en continuar la obra como estaba prevista en el auto del 31 de diciembre de 1605, que se vigilara mantener el rumbo señalado el 16 de agosto de 1606 y que, de ser necesario, se entibase la galería llevando la madera necesaria. Además, ordenaba que el veedor y el sobrestante cuidaran de que los indios asignados para trabajar en las lumbreras, el socavón y el desmonte no se ocupasen en hacer otras cosas, excepto del trajín de maderaje y de la extracción de mineral los días que les tocase, hecho éste que sería vigilado por el corregidor aplicando en su incumplimiento la pena de privación de sus oficios (AGI. Patronato, 239, R. 43, BI. 8, F. 2r-8r).

Incluso el día antes de su partida para Lima (19 de diciembre de 1606), el oidor Arias redactó un auto con instrucciones complementarias mediante las cuales mandaba al corregidor o persona a quién competiera hacer el repartimiento de los indios, que enviase 120 a trabajar en las lumbreras y 24 al socavón los cuales, debido a la importancia de estas obras, habían de ser de los mejores y más trabajadores que vinieren a la mita de Huancavelica (PMR. Ms. 330/135, F. 55).

El 26 de diciembre de 1606, posiblemente ya en Lima, Arias escribía al antiguo virrey Luis de Velasco a Méjico una carta en la que le informaba de que las obras de las lumbreras, socavón y desmonte se estaban realizando. Al respecto mostraba su preocupación por la continuidad de dichas labores si la Corona no enviaba ingenieros y maestros expertos, mientras que si llegaban no faltarían minerales en el futuro. Además, asumía su falta de preparación para dirigir tales obras y refería su mal estado de salud que achacaba al riguroso clima de Huancavelica (AGI. México, 27, N ${ }^{\circ}$ 24, BI. 5, F. 3r).

Una vez en Lima, Arias informó a la Audiencia que le renovó su confianza encargándole regresar a Huancavelica para continuar las obras iniciadas, con gran desagrado del oidor que deseaba desligarse de dicha tarea. Tras superar una dolencia, regresó a Huancavelica llegando a la villa en 1 de julio de 1607.

En su ausencia, a principios de dicho año 1607, habían sucedido graves problemas en las minas pues entraron en ellas fuertes corrientes de lodos producidos por las lluvias. Además, las lumbreras y el socavón no habían progresado suficientemente. En lo que respecta a éste, la dureza de la roca era difícil de 
superar, y más con la escasa mano de obra disponible (una dúa de doce obreros), absolutamente insuficiente para la magnitud de la obra. Ozores había previsto trabajar las 24 horas de forma continua, pero Arias consideró injusto obligar a los operarios del socavón a realizar un esfuerzo mayor que el resto del peonaje de la mina; sólo cuando apreció el importante retraso de la obra autorizó también el trabajo nocturno, con lo cual se aceleró algo el ritmo del avance. A finales de 1607 la Audiencia emitió un auto para que Ozores inspeccionara las obras realizadas por Arias. Ambos las recorrieron y Ozores mostró su disconformidad con la forma en que se habían ejecutado dichas labores llegando a convencer de ello incluso al propio Arias que así lo reconoció, aunque no comentó nada del caso a los mineros. Terminada su misión, Ozores viajó a Lima para recibir al nuevo virrey que estaba por llegar. Arias, por su parte, solicitó a la Audiencia licencia para regresar a la ciudad de Los Reyes, lo que hizo el 17 de diciembre de 1607 cuando el socavón solo medía 29 varas $(24,5 \mathrm{~m})$ de longitud. La Audiencia nombró sustituto a su hermano, Miguel Arias de Ugarte, anteriormente alcalde de minas de Popayán (actual Colombia) (Lohmann, 1949).

El nuevo virrey, Juan de Mendoza y Luna, marqués de Montesclaros, tomó posesión de su cargo el 21 de diciembre de 1607. Apenas Ilegado a Lima, Ozores mantuvo intensas conversaciones con él sobre las minas de Huancavelica mostrándole sus temores de que se vieran afectadas por las lluvias y se repitieran los graves sucesos acaecidos a principios de 1607. Poco después llegó Arias a la ciudad de Los Reyes, y el virrey le comentó las inquietudes expresadas por Ozores que el marqués de Montesclaros había hecho suyas, pero Arias le contestó que nunca antes habían estado las minas tan seguras. En respuesta, Ozores pidió licencia para emitir un dictamen por escrito pero se le ordenó no tratar más del asunto. Sin embargo, en febrero y marzo de 1608, los fuertes temporales de lluvias ocasionaron nuevos deslizamientos de lodos que entraron en las minas, ocasionando muchos daños e, incluso, varios muertos. Conocida la noticia en Lima, el virrey convocó a Ozores para que le explicase las causas del desastre, el cual le recomendó que visitara personalmente las minas para que apreciara la situación in situ, sin las influencias de opiniones ni informes diversos. Desde el punto de vista de la producción, la situación era también grave pues los asentistas apenas entregaban una quinta parte de los cupos y la deuda a favor del Erario ocasionada por la baja ley de las zonas en explotación y el adelanto del pago de jornales a los operarios indios de desmonte, lumbreras y socavón ascendía a casi 300.000 pesos (Lohmann, 1949).
Un documento fechado hacia 1622 señalaba que ésta había sido la época de menor actividad y mayores problemas de la mina porque, debido al tajo abierto, se había derrumbado el interior permaneciendo así más de cuatro años, llenándose los huecos y galerías con aire tan contaminado que todo aquel que entraba en contacto con él, moría súbitamente (BNE. Ms. 3041, F. 273r).

Coincidente con los enterramientos de las explotaciones, el 5 de febrero de 1608 Ozores presentó el ya citado parecer sobre las minas al virrey. En lo relativo al socavón que se estaba dando, además de lo comentado anteriormente en relación con el inicio de obra, en estos momentos, transcurridos dos años desde su inicio, decía que, en su opinión, iba errado por haberse empezado en roca (cantería), siendo que la experiencia de doce socavones en Potosí mostraba que los que se habían excavado en tierra suelta eran fáciles de trabajar mientras que si se encontraba con roca dura las dificultades aumentaban sobremanera. Avisaba, igualmente, de que aunque en la superficie no aparecieran rocas, podía haberlas en el subsuelo. Sin embargo, reconocía que por el lugar por el que iba el socavón se podía encontrar terreno blando. Por otra parte, proporcionaba indicaciones prácticas para construir la bocamina y para superar el problema de la ventilación que se presentaría en una labor tan larga, perforando pocillos verticales. También se oponía a la idea existente de realizar un segundo socavón por otro sitio pues obligaría a que los indios trabajasen algunos días de fiesta (BNE. Ms. 3041, F. 159v-161r).

Entendiendo la gravedad de la situación, el marqués de Montesclaros llamó a algunos de los mineros más experimentados a Lima, a los que pidió su opinión (BNE. Ms. 3041, F. 273r). Estando allí Juan de Sotomayor por el motivo dicho, el 17 de junio de 1608 emitió un parecer sobre lo que habría que hacer en las minas de Huancavelica, dando un repaso a las distintas obras que se estaban realizando en el desmonte, las lumbreras y el socavón. Respecto de éste era plenamente consciente de la larga duración que tendría la obra, no obstante lo cual la aprobaba por su importancia para el futuro de la mina, aunque debería efectuarse con garantías técnicas controlando la dirección de la galería mediante compás y cartabón y construyendo periódicamente respiraderos verticales sobre la traza de la galería (BNE. Ms. 3041, F. 115r).

Otro minero también consultado fue José Ribera. En lo tocante al socavón mostraba serias dudas sobre la conveniencia de realizarlo debido a su longitud y a la existencia de los graves problemas que aparecerían durante la obra, especialmente en el avance cuando la galería topase con roca dura, en la estabilidad y seguridad de la labor cuando atravesase terreno suelto y 
en la ventilación, con el consiguiente envenenamiento de los operarios por el polvillo producido ya que dudaba que los pocillos fueran suficientemente eficaces (BNE. Ms. 3041, F. 117r-117v).

\section{Visita del virrey Juan de Mendoza, marqués de Mon- tesclaros, a Huancavelica}

Atendiendo la recomendación de Ozores y a la vista de las dispares opiniones de los mineros consultados, el marqués de Montesclaros decidió viajar a Huancavelica para inspeccionar personalmente las minas, cosa insólita que nunca antes había realizado un virrey.

El 6 de julio de 1608 Montesclaros emprendió el viaje acompañado de un séquito que incluía a Fernando Arias de Ugarte, ya repuesto en su cargo de oidor de la Audiencia. Ozores se incorporó en Castrovirreina cuando la comitiva pasó por allí. Llegado a la villa, el virrey se informó sobre el asunto de la mano de obra, constatando que la forma en que se hacían las faenas no era ni de mayor peligro ni con mayores agobios que las usuales en las labores subterráneas. También supo que muchos indios acudían voluntariamente a trabajar en las minas atraídos por los crecidos jornales que se pagaban. Comprobó que las mermas en los empadronamientos de temporeros no obedecían a la mortandad de los mitayos sino a que éstos abandonaban los pueblos donde residían para ir a las comarcas exentas de aportar obreros a la mita o a las haciendas y estancias cuyos propietarios los ocultaban para que trabajasen en ellas a salvo de la mita. Visitó también el hospital al que aumentó sus recursos económicos y de personal, constatando que no había ningún azogado en él. Al tercer día visitó las minas activas del cerro guiado por Ozores, recorriendo hasta sus más pequeños recovecos, y aguantando el hedor producido por el polvo, los humos de las velas y antorchas, el sudor y los excrementos de los obreros. El 2 de agosto volvió a subir el virrey a las minas acompañado de Arias, Ozores, el minero Juan de Sotomayor y otros; en esta ocasión recorrieron la Descubridora y Correa de Silva. Una tercera visita al día siguiente le llevó a las lumbreras en construcción, cuyo trabajo suspendió temporalmente por recomendación de los expertos (Lohmann, 1949). Visitó también el socavón de Nuestra Señora de Belén, penetrando sin contratiempo las 53 varas $(42 \mathrm{~m})$ perforadas (BNE. Ms. 3041, F. 123v). Dentro de él comprobó la dureza de la roca que se estaba atravesando, interesándose por la forma en que podría superarse este problema con mayor facilidad. Además, mandó medir el rumbo de la galería, que se comprobó que era el previsto (López de Caravantes, 1987).
Por otra parte, los responsables de la obra, conscientes de que el socavón estaba alineado y discurriendo dentro de una corrida de roca muy resistente, aseguraron que las más de 600 varas (502 m) que aún restaban para su finalización era imposible que se perforaran antes de cuarenta años. En esta tesitura, fray Tomé de Acosta, que tenía experiencia en el trabajo minero, propuso un proyecto alternativo que consistía en sustituir el socavón por una combinación de pozo y galería que salía de su fondo dirigida a cortar la zona virgen de la mina San Jacinto justo debajo de la lumbrera de Nuestra Señora. La previsión era que la obra duraría dos años. Ante esta situación, el virrey decidió apostar por la propuesta de fray Tomé y suspender la obra del socavón durante este tiempo.

El asunto se hizo oficial en la instrucción sobre intervenciones en las minas que el virrey entregó al gobernador Miguel Arias de Ugarte el 11 de septiembre de 1608. En ella se describía la propuesta de fray Tomé y se le ordenaba paralizar la labor en el socavón durante dos años, haciendo especial hincapié en que tanto el veedor de las minas como la persona a cuyo cargo estuviera el gobierno superior de ellas, debían conservar la obra realizada y limpiary sacar las tierras y piedras que en él cayeran durante el tiempo de suspensión de los trabajos para que, en el caso de que se hubieran de continuar, se pudiera hacer aprovechando íntegramente las cincuenta varas que había excavadas (BNE. Ms. 3041, F. 147v).

La idea de fray Tomé era bastante novedosa (BNE. Ms. 3041, F. 147v-148r). Miguel Arias de Ugarte, el 15 de septiembre de 1608, nombró a Fray Tomé sobrestante de todas las minas, encargándole que realizara los cometidos señalados en la instrucción del día 11 (PMR. Ms. 330/135, F. 57-64). En dicha obra fray Tomé aseguró que se trabajaría con maquinaria y artificios, cuyos modelos exhibió, destinados a extraer rápidamente los escombros (Lohmann, 1949). Sin embargo, la mayor parte de los encargos de la instrucción dada a Miguel Arias y a fray Tomé, no tuvo efecto porque el fraile falleció cuando apenas se habían iniciado los trabajos. La labor se abandonó tanto por falta de un valedor como porque se demostró su inutilidad (Lohmann, 1949; BNE. Ms. 3041, F. 167r).

Otra medida adoptada por el virrey con objeto de resolver en lo posible los abusos y problemas que estaba ocasionado el vigente asiento de 1604, fue adelantar dos años su conclusión, disponiendo otro nuevo el 1 de noviembre de 1608 que duraría hasta el 31 de octubre de 1610. En él se comprometía una mita de 2.300 indios, de los que 150 se dedicarían a los desmontes y a limpiary reparar las minas (BNE. Ms. 3041, F. 135r). 


\section{El socavón de Nuestra Señora de Belén durante los gobiernos de Ozores de Ulloa y Solórzano Pereira}

El 18 de noviembre de 1608, Pedro Ozores de Ulloa, por comisión del marques de Montesclaros, fue nombrado administrador de la mina (AGI. Patronato, 239, R.44, BI. 3. $\mathrm{N}^{\circ} 1$ ). Meses más tarde, el 16 de junio de 1609 fue nombrado interinamente gobernador de la viIla, cerro y minas y, finalmente, el 29 de mayo de 1610 el marqués de Montesclaros lo designó gobernador efectivo de Huancavelica, quedando desde ese momento refundidas en una sola persona los títulos de administrador de la mina y de corregidor de la provincia. En 1609 llegó a Huancavelica el grupo de expertos de Almadén tan largamente demandado (Lohmann, 1949). Estaba integrado por Juan de Buendía, nombrado veedor en España por cédula de 14 de mayo de 1607 (AGI. Contratación, 5792, L.2, F. 398r-398v), Gaspar Guerra, Andrés Muñoz, Martín Sánchez y varias personas auxiliares. Buendía, en su cargo de veedor, dirigió a partir de entonces todas las obras en las minas, lo que supuso una inmediata mejora de las condiciones en ellas (Lohmann, 1949). Buendía inspeccionó las minas y sus reparos $y$, al comprobar que iban sin la traza y seguridad convenientes, empezó a instalar entibaciones de madera a modo de bóvedas y cimbras y a construir todos los reparos necesarios para que las minas y socavones se asegurasen y los desmontes sueltos no cayesen y los cegasen (BNE. Ms. 3041, F. 149r). En un sitio especialmente rico, el Sacadero, pero con tan mala ventilación que en él no ardían bien las velas, preparó una especie de ventilador con aspas de madera, denominado abanillo, que levantaban aire con lo que ardían mejor (BNE. Ms. 3041, F. 466r).

En lo tocante al socavón, los recién llegados asesoraron a Ozores sobre el rumbo que se le había dado a la galería; realizadas las mediciones se comprobó la necesidad de variar la orientación cuando se retomaran las labores en él.

Durante 1610 continuaron las reparaciones en las minas con gran eficacia, hasta el punto de que, a comienzos de 1611, las explotaciones estaban consolidadas. Las lumbreras de Arias de Ugarte habían sido restauradas permitiendo trabajar los frentes de las minas Nueva y San Jacinto; tenían 100 m de profundidad y cada una disponía de un torno en la boca mediante el cual se extraía tanto el mineral como el escombro. Sin embargo, las numerosas obras que hubo que realizar en las minas detrajeron gran número de operarios de las labores productivas, lo que resultó en una bajada significativa de la producción de mercurio que llegó a ser preocupante tanto para los mineros como para la Corona. Puesto que en aquellos momentos solo se trabajaba de día, el marqués de Montesclaros autorizó el trabajo nocturno lo que mejoró la productividad general. A pesar de los problemas existentes, se renovó dos años más el asiento de 1608.

Posteriormente, en 1613, como el estado de las minas era pujante se decidió volver a ampliar el asiento de 1608 otros dos años más. Sin embargo, los abusos de los gobernantes y sus adláteres colmaron la paciencia de los mineros que comenzaron a denunciar las corruptelas de Ozores, Buendía, Guerra y otros que aprovecharon indebidamente en beneficio propio la bonanza del mineral. Dadas las características del escándalo, el virrey envió a Huancavelica a comienzos de 1615 a Diego de Vargas para que hiciera averiguaciones secretas acerca del estado de las minas y de los excesos que ocurrían en ellas; sin embargo, nada se supo del resultado de estas averiguaciones en las que estaban implicados los responsables de las minas, algunos mineros y muchos indios (Lohmann, 1949).

En estos años, las autoridades consideraron que no era momento de retomar la construcción del socavón de Nuestra Señora de Belén decantándose por las lumbreras y manteniéndose la obra en suspenso.

Nombrado Francisco de Borja y Aragón, príncipe de Esquilache, nuevo virrey del Perú el 19 de julio de 1614, hizo su entrada en Lima el 18 de diciembre de 1615. Apenas llegado, los mineros le plantearon formalizar un nuevo asiento, vencido el de 1608 y sus tres prórrogas pero, mientras se discutían los pormenores, por auto de 28 de abril de 1616, el virrey extendió la validez del asiento de 1608 hasta finales de año. Otro problema acuciante que se encontró el príncipe de Esquilache fue el del desprestigio del gobernador Ozores el cual, rápidamente, se trasladó a Lima para hablar con él. El 18 de marzo de 1616 Ozores había preparado una memoria que abarcaba desde los tiempos del virrey Toledo hasta aquellos momentos (Lohmann, 1949); naturalmente, según ella, la honradez del autor en las tareas que desarrolló durante este tiempo quedaba fuera de toda duda (BNE. Ms. 3041, F. 164 r-171 v). Poco después, el 20 de mayo, Ozores escribía al monarca comentando alguna incidencia de las minas, tal como que el virrey se había dado un año para decidir si, para mejorar la ventilación, se daban dos nuevas lumbreras o se continuaba el socavón de Nuestra Señora de Belén. No obstante, las verdaderas razones de su carta fueron, por una parte, contrarrestar la campaña de denuncias en su contra denunciando, a su vez, las malas prácticas de los mineros y, por otra, comunicar a la Corona que se sentía abandonado por las autoridades coloniales; por todo ello, Ozores solicitaba que se le diera licencia para dejar el cargo (AGI. Patronato, 239, R.44, BI. 1, Nº 3-4). Posiblemente se estaba cubriendo las espaldas ante lo que presagiaba que iba a llegar. 
Las continuas denuncias contra el gobernador Ozores consiguieron que el virrey lo destituyera junto con sus asesores Buendía y Guerra. Mientras tanto, la producción de las minas continuaba aunque algunos lugares especialmente ricos, como el denominado Sacadero, habían sido expoliados por Ozores, Buendía, Guerra y otros que extrajeron los apoyos para beneficiarse personal e ilícitamente de sus minerales (BNE. Ms. 3041, F. 175r-177 v, 185r-192v). Como consecuencia de ello, el 6 de octubre de 1616 colapsó el Sacadero, muriendo dos españoles y diez indios.

A la vista de la situación, el virrey decidió enviar a Huancavelica una persona de autoridad contrastada para que averiguara si las infracciones que se estaban denunciando eran ciertas. El nombramiento recayó en el doctor Juan Solórzano Pereira el cual, por provisión de 17 de septiembre de 1616, asumió los cargos de gobernador, justicia mayor y juez visitador de las minas y funcionarios de la Caja Real. Solórzano llegó a Huancavelica el 8 de octubre, dos días después del hundimiento del Sacadero, y tomó posesión el 10, cesando al gobernador Ozores e iniciando las investigaciones sobre sus actividades, las de Buendía y las de otros denunciados (BNE. Ms. 3041. F. 442r-445r, 456r-469v). Tenía también los encargos de indagar sobre los fraudes que se cometían al Erario, y de recabar información para celebrar un nuevo asiento con los mineros (Lohmann, 1949).

En marzo de 1617 Solórzano ya tenía claro que la corrupción era general y que si aplicaba la ley a los inculpados, se debería desterrary requisar la mitad de los bienes a todos ellos, lo que sin duda influiría en la marcha de las minas. Por ello el 20 de marzo comunicó al rey que había acordado con el virrey que se pactara un acuerdo (composición) con los implicados según el cual debían satisfacer los quintos no abonados a la Corona, de lo cual estaban tratando en esos momentos (AGI. Patronato, 239, R.46, BI. 3. N ${ }^{\circ} 2-3$ ). Esta cantidad sumaba 25.000 pesos (Lohmann, 1949). La grave situación también fue notificada a la Corona por el oficial real Fernando Díaz de Villalba (AGI. Patronato, 239, R.46, BI. 2. No 2).

Durante su mandato, Solórzano visitó con frecuencia las minas, modificando algunas prácticas para mejorar la seguridad, estabilizando las labores inmediatas al Sacadero con la ayuda del sobrestante Francisco Romero Mudarra, ya que Buendía y Guerra estaban cesados y sometidos a investigación.

Para tratar de mejorar la ventilación, tras numerosas consultas, Solórzano convenció al virrey que las dos grandes lumbreras diseñadas en la época del marqués de Montesclaros por Ozores y Buendía y pendientes de construir no eran las obras más adecuadas por sus complicaciones técnicas, decantándo- se por la reanudación del socavón de Nuestra Señora de Belén. Decidida esta cuestión, el 26 de septiembre de 1617, pese a su situación, Buendía, Guerra y otros reconocieron el abandonado socavón calculando la profundidad en su extremo final en 196 varas (164 m) y su longitud en 688 varas (575 m) (BNE. Ms. 3041, F. 493r-493v).

El 9 de octubre de 1617 se retomaron las obras del socavón dirigidas por Francisco de Quirós, cosmógrafo mayor del virreinato, y Fabián González Caldera. Como veedor de la obra se designó a Fernando Díaz de Villalba, con experiencia en Almadén y Potosí (Lohmann, 1949). Francisco Romero Mudarra fue nombrado sobrestante. Lo primero que se hizo fue limpiar la galería y medirla, hallándose una longitud de 54 varas. Después, el virrey envió a Francisco de Quirós para que igualmente midiese la mina y viese la profundidad que tenía y la longitud del socavón que faltaba por excavar. Habiéndose calculado dos veces, una Quirós y otra los veedores, se obtuvieron similares resultados: la mina tenía una profundidad de 190 varas en el punto de corte y la distancia calculada entre la labor subterránea y el socavón era de 680 varas (BNE. Ms. 3041, F. 500v-501r).

En una carta de Fernando Díaz de Villalba al rey fechada el 8 de abril de 1618 le comunicaba el lento avance del socavón debido a la dureza de las rocas existentes en su camino y proponía la construcción de un segundo socavón paralelo para poder darle respiración pues consideraba que si se perforaba solo uno, no podría finalizarse por falta de ventilación (AGI. Patronato, 239, R.47, F. 1v). La construcción del segundo socavón era una buena idea pero muy costosa de llevar a la práctica en aquella época y, además, alargaría aún más la duración de la obra principal.

Por su parte, el minero Jorge Fonseca era más optimista, considerando que la galería era muy importante para el bien de los indios y el futuro de la mina, matizando que el socavón se estaba construyendo a costa de los mineros (AGI. Patronato, 239, R.48, BI. 1. N ${ }^{\circ} 6$ ).

El virrey transmitió a la Corona la decisión de retomar la obra del socavón en carta de 16 de abril de 1618 , recibiendo su apoyo en la respuesta de 16 de marzo de 1619 (BNE. Ms. 2969. F. 969). Desde este momento, el socavón se convirtió en la principal labor para la futura ventilación de las minas, ofreciendo, además la ventaja de poder sacar por él el mineral cargado en carretones. La obra había parado en 1608 al haber topado con roca muy dura, la misma que estaba siendo tan costosa de atravesar en su reanudación.

Un nuevo asiento firmado con los mineros el 2 de abril de 1618 garantizaba, de alguna forma, la mano de obra necesaria para el socavón concediendo 2.200 mitayos a los trabajos mineros (Lohmann, 1949). Los 
destinados al socavón no podrían ser muchos dadas las pequeñas dimensiones del frente de trabajo y el reducido avance que, como era lógico, producía escaso volumen de roca estéril que sacar a la bocamina.

Mientras tanto, la investigación contra Ozores y sus auxiliares, pese a la probanza de las acusaciones por numerosos testigos, se saldó únicamente con la condena de pagar 500 pesos a Ozores, 2.000 pesos a Buendía y 3.000 pesos a Guerra. Todos ellos fueron repuestos en sus cargos. El 15 de diciembre de 1618 se expidió el nombramiento de Ozores por lo que poco después Solórzano dio por cumplida su misión y abandonó Huancavelica.

Las obras del socavón siguieron bajo la dirección de Francisco de Quirós el cual viajó a Lima para informar al virrey de su estado, posiblemente porque consideraba que su labor estaba concluida al recobrar Juan de Buendía su puesto de veedor de las minas. Una vez finalizado su objetivo en la capital, Quirós envió en diciembre de 1619 un memorial al virrey proponiendole instruir a Juan de Buendía y al sobrestante del socavón para que continuaran la obra como estaba prevista, para lo cual se ofreció a permanecer cuatro meses en Lima como asesor cobrando el mismo salario de veedor que percibió en Huancavelica, pagadero por la Caja Real de la villa. El virrey aceptó el ofrecimiento pero solo durante tres meses, emitiendo la correspondiente provisión el 30 de diciembre de 1619 (BNE. Ms. 3041, F. 495r-495v).

El 3 de marzo de 1620, Francisco de Quirós presentó en Huancavelica la citada provisión ante el nuevamente gobernador Ozores, entre otras cosas, para concretar las cuestiones del pago de su asesoramiento en la Caja Real allí ubicada. Para que dicho asesoramiento tuviera el efecto deseado, Quirós solicitó la ayuda de un carpintero y materiales para construir algunos instrumentos a fin de guiar el socavón y la autorización para que dichos gastos fueran consignados a Buendía. Ozores lo aprobó pidiendo a Quirós que indicase el lugar donde había de calar el socavón en la mina, señalase con mojones el sitio en la superficie del terreno y comunicase el rumbo que había de llevar la galería. Asimismo debía medir la profundidad, tanto de la mina como del socavón, y calcular la vía de evacuación del agua subterránea con que se había topado o pudiera toparse la obra. Igualmente debía enseñar al gobernador y a los veedores y sobrestante del socavón a usar los instrumentos empleados para realizar las mediciones y entregar todos ellos, además de dejar sus planos constructivos por si se dañaban y hubiera que duplicarlos (BNE. Ms. 3041, F. 495v-497r).

En escrito del 4 de abril de 1620, Ozores certificaba que Francisco de Quirós había cumplido su compromiso asesorando al factor Fernando Díaz de Villaba, oficial real de la Real Hacienda, a Juan de Buendía, veedor, y a Antonio Manuel, sobrestante del socavón. Quirós les había enseñado lo convenido, entregado los instrumentos (incluido un planisferio suyo de plata que regaló) y dibujado en papel sus medidas por triplicado. Por ello, Ozores, a la vez que comunicaba al virrey que el antiguo veedor había cumplido los mandatos recibidos, autorizaba que se le abonasen los salarios pactados (BNE. Ms. 3041, F. 497r-497v).

\section{El socavón durante el mandato del virrey marqués de Guadalcázar}

En los años 1621 y 1622 hubo cambios notables de gobernantes. Ozores finalizó su mandato en junio de 1621 , habiendo estado más de dos lustros administrando Huancavelica, hecho que no tuvo repetición (AGI. Patronato, 229. R.60). Le sucedió en el cargo el general Fernando de Córdoba y Figueroa, nominado el 12 de noviembre de 1621 (Lohmann, 1949). A su vez, el 18 de abril de 1621 concluyó el período gubernativo del príncipe de Esquilache en el Perú, apresurándose a dejar Lima sin esperar a su sucesor (Zaldivar, 2016). Mientras llegaba el nuevo virrey, ocupó interinamente el cargo el presidente de la Audiencia de Los Reyes, Juan Jiménez de Montalvo, que lo ejerció hasta que el 25 de julio de 1622 arribó el nuevo virrey Diego Fernández de Córdoba, marqués de Guadalcázar (Hanke, 1978).

En esta época Huancavelica no era capaz de suministrar el mercurio que necesitaban las minas de plata por lo que se sucedieron las peticiones a España para que se remitiera el mercurio necesario. Sin embargo, en estos momentos, recurrir a Almadén no era solución ya que la mina estaba al límite de su capacidad y su producción la acaparaba Nueva España. Ante esta necesidad imperiosa la Corona firmó con Federico Oberolz un contrato de suministro de 4.000 quintales anuales de azogue desde Idria (Eslovenia) durante cuatro años, que se entregarían en Sevilla o Cádiz. El contrato, de fecha 29 de abril de 1621, fue renovado en 1626 por igual periodo de tiempo. Mediante este proceder, la Corona eligió compensar el descenso de producción en Huancavelica comprando mercurio en el extranjero en lugar de forzar a los indios de Huancavelica a realizar trabajos mayores o aumentar el número de mitayos. Al respecto, es reseñable que, según las cuentas del virreinato peruano, el mercurio que llegaba de España y estaba disponible en el puerto de El Callao era apenas la mitad del que se expendía por la Casa de Contratación en Sevilla, desapareciendo tan gran cantidad por negligencia achacable a los oficiales reales.

En 1622 expiró el asiento celebrado con príncipe de Esquilache para el arrendamiento de las minas. 
El marqués de Guadalcázar investigó cuales eran las existencias de mercurio almacenadas $y$, asegurado el suministro periódico desde España, decidió reducir la cantidad de mitayos, limitando la carga impuesta a cada comarca, disminuyéndola del séptimo al noveno de la población tributaria empadronada; de esta manera quedarían excluidas de atender la mita 800 personas. El nuevo asiento se firmó el 1 de febrero de 1623 y tendría una duración de cuatro años, a contar del primer día del mes siguiente. El número de mitayos se redujo hasta 1.400 , disminuyendo el rendimiento anual de cada uno de 3 a 2 quintales de azogue. De los citados trabajadores se destinarían 180 para dedicarlos a la excavación de Nuestra Señora de Belén, corriendo los mineros con el gasto de su salario sin que, además, pudieran beneficiarse del mineral que se extrajese en la obra (Lohmann, 1949).

No obstante, la situación en las minas dejaba mucho que desear. La corrupción había vuelto a implantarse, si es que alguna vez dejó de haberla, recordando los hechos que se denunciaron durante el mandato de Ozores. Además, encomenderos, doctrineros, corregidores y curacas también abusaban de sus posiciones dominantes para medrar en detrimento del pueblo llano. Esta situación fue denunciada por Juan de Aponte en un memorial escrito el 24 de abril de 1622 en el que dedica varios comentarios a la situación en las minas de Huancavelica. Aponte tenía muy claras las causas de la degradación del trabajo minero: la avaricia de todos, los robos de mineral de muchos y la connivencia y complicidad de la administración colonial (Aponte, 1622). El socavón de Nuestra Señora de Belén no era ajeno a estas corruptelas pues el sobrestante español que lo administraba, de los 30 indios asignados, ocupaba solo 15 en la galería dedicando el resto a trabajar en sus negocios particulares. Los indios de mita trabajaban seis meses en el socavón y se alimentaban con maíz, queso, pan y chicha. El veedor les vendía esta comida a precio muy caro y se la descontaba de sus jornales, de forma que lo que debía pagarles se lo quedaba el sobrestante por los alimentos que les había vendido; acabada la mita, los indios volvían a sus pueblos de origen sin dinero alguno. Los veedores, que tenían obligación de remediar esta situación y denunciarla al gobierno o al corregidor, no lo hacían porque ellos también practicaban las mismas corruptelas con los indios del desmonte, de manera que unos y otros se encubrían, todos robaban y nada se remediaba (Aponte, 1622).

En este año de 1622, el 18 de julio, el minero Juan de Sotomayor (hijo), proporcionaba algunas noticias sobre el socavón, informando de que parecía que se había superado la barrera rocosa que tantos años demoró atravesar y que ya se habían perforado 150 varas
(125 m) (BNE. Ms. 3041. F. 281r). Sin embargo, es fácil de colegir que el avance del socavón podría haber sido mucho mayor sin las corruptelas denunciadas por Aponte. En cualquier caso, el virrey era consciente de estos problemas pues en el nuevo asiento se conminó al veedor para que aplicara íntegramente el cupo de 30 obreros en dos turnos de 15 cada uno, cambiándolos semanalmente al concederse licencia para que pudieran trabajar las 24 horas del día en el socavón. Cada turno estaría a cargo del veedory de un oyarico. Para adelantar la excavación, el arquitecto Juan Martínez de Arrana estudió de nuevo la traza de la galería redirigiéndola.

En marzo de 1624 se nombró nuevo gobernador de Huancavelica a Jusepe de Ribera y Dávalos el cual, como experto minero y buen conocedor de las minas que era, comprobó que la traza era errónea, teniendo que ser rectificada a mediados de 1624 por el agrimensor Juan de Estrada (Lohmann, 1949).

\section{El virrey Luis Jerónimo de Cabrera y Bobadilla, conde de Chinchón y su impulso a la obra del socavón}

Cuando el virrey Luis Jerónimo de Cabrera y BobadiIla, conde de Chinchón, asumió el cargo tras entrar en Lima el 14 de enero de 1629, hizo recuento de las reservas de azogue en los almacenes reales, hallando solo 2.800 quintales. En esa época, la producción de las minas era de 2.000 quintales anuales, mientras que el suministro demandado por el Perú sumaba 10.000. De las remesas enviadas desde España, llegaba al virreinato solo una pequeña parte (en enero de 1630, 543 quintales de los 4.000 remitidos). Investigando la situación de las minas de Huancavelica, el virrey constató que no ofrecían perspectivas demasiado halagüeñas para el futuro debido a que las labores estaban muy profundas y a que el peonaje era escaso; apenas la mitad de los mitayos consignados en el asiento vigente trabajaba en las minas siendo la causa principal la negligencia de los corregidores para congregarlos. Por estas razones, el virrey creyó oportuno concertar un nuevo asiento que se acomodara a las circunstancias y necesidades del momento. El primer paso fue requerir un aumento de la llegada de mercurio desde Idria hasta 6.000 o 7.000 quintales anuales lo que, por otra parte, resultaba más beneficioso a la Corona, en términos económicos, que el producido en Huancavelica. La alternativa que proponía el virrey era aumentar sensiblemente la producción de Huancavelica aunque, fuera cual fuera la solución adoptada, debía garantizar un suministro regular de azogue para evitar épocas de carestía o de sobreabundancia en los almacenes (Lohmann, 1949). 
Las negociaciones para implementar el nuevo asiento fueron largas y complicadas, especialmente en lo referente al reparto de los mitayos en las minas. Finalmente, el convenio se firmó el 27 de junio de 1630, entrando en vigor el 1 de julio por un mínimo de tres años, esperándose que en ese plazo la Corona adoptase una solución respecto del suministro del mercurio a las minas peruanas, bien ordenando que todo el mercurio llegara importado de España, bien impartiendo instrucciones sobre lo que debía ejecutarse en el Perú. En el asiento sólo se admitieron 26 asentistas que, previamente, debían abonar las deudas pendientes con el Erario. Para el trabajo se consignó una cuota de 1.400 mitayos de los que se detraerían 160 para aplicarlos a la limpieza de escombros, obras de mantenimiento de las galerías y perforación del socavón Nuestra Señora de Belén. De aquella cantidad, realmente sólo se repartieron 1.300, pues el virrey retuvo un centenar, que denominó indios de premio, los cuales distribuiría el gobernador entre aquellos asentistas que más adelantasen en las labores y mejor cumpliesen sus obligaciones. Las faenas en el socavón estarían al cuidado de un veedor, siendo ésta la única obra en la que autorizó el trabajo nocturno. Cada turno estaría formado por doce obreros que se alternarían cada semana en el trabajo diurno/nocturno. Para trabajar con una barreta se adjudicaba una compañía de dos mitayos, de suerte que mientras uno descansaba, el otro picaba. El mineral que se obtuviere en el socavón sería propiedad de los asentistas los cuales, por su parte, debían satisfacer los jornales y proporcionar herramientas para el trabajo. Por el contrario, el mineral desprendido de muros, pilares y bóvedas en la mina pertenecería directamente al Estado, que lo vendería en la bocamina al mejor postor (Lohmann, 1949).

En agosto de 1630 el virrey nombró al doctor Juan de la Celda administrador de Huancavelica, el cual realizó todos esfuerzos posibles para obtener elevados rendimientos en la producción de mercurio. Sin embargo, tropezó con la insalvable dificultad de la falta de obreros, que no llegaban a mil cada año, con lo cual era absolutamente imposible acometer todas las faenas de la extracción y beneficio del mineral. Por eso, la labor de Celda se limitó a pequeñas obras de refacción, principalmente a la consolidación de los contrafuertes de las galerías (Lohmann, 1949). En relación con el socavón, el gobernador comprobó que el camino de subida de la villa al socavón era peligroso por lo que hizo abrir otro por terreno seguro que incluía dos puentes de madera para atravesar el arroyo Yananaco y poder transitar con seguridad y facilidad (López de Caravantes, 1987).

Cuando el conde de Chinchón se hizo cargo del virreinato, el socavón apenas había avanzado 177 varas
(148 m) desde su inicio, 22 años antes. Sin embargo, durante su mandato, la galería experimentó un avance decisivo aunque el virrey no la pudo ver terminada ya que la finalizaría su sucesor. Pese a la importancia del socavón para la ventilación de las galerías inferiores de la mina, la perforación se llevaba con extrema lentitud. En esa época trabajaban en la labor algunos reos españoles que, de esta forma, purgaban sus penas; estaban ayudados por dos turnos de obreros indígenas conformados por escasos efectivos. La longitud de la galería y el hecho de estar orientada a sotavento de las corrientes de aire dominantes en Huancavelica, hacía dudar a algunos mineros de la finalización de dicha labor pues, para trabajar en ella, sería necesario perforar periódicamente conductos verticales que crearan los circuitos de ventilación requeridos para la circulación del aire. El virrey, decidido a concluir el socavón, recurrió al capitán Jerónimo Pérez de Anticona, minero que había empleado la pólvora para beneficiar sus denuncios en el cerro de Colquimacay, situado en el yacimiento de Santiago de Guadalcázar, en Canta (Lohmann, 1949).

El empleo de la pólvora en minería era un proceso novedoso en el ámbito hispano. Las primeras noticias que se tienen de su uso fueron en ciertas minas de Italia y Alemania en 1580. En España, se sabe que el arranque de roca con pólvora fue propuesto en 1605 en las minas de San Ginés (Murcia) pero se ignora si, finalmente, se empleó (Sánchez, 1989). En Almadén la introdujo el superintendente Miguel de Unda y Garibay en 1698) y su uso ya era común en 1703 (Mansilla and Iraizoz, 2012).

En el mes de noviembre de 1631, Pérez de Anticona realizó varias demostraciones de la eficacia de la pólvora que fueron coronadas por el éxito (Lohmann, 1949). De esta forma, el conde de Chinchón dio orden de que se emplearan cuñeras de pólvora para avanzar el socavón (BNE. Ms. 3080, F. 28r). En realidad, la pólvora se introducía en unos agujeros de un metro o metro y medio de longitud, posiblemente envuelta en papel, se acuñaba con tacos y luego se la prendía con una mecha. De esta forma se arrancaba con poco esfuerzo lo que mediante picos y barretas costaba muchos días. El conde de Chinchón calculaba que si hasta entonces se habían avanzado diez metros al año, utilizando la pólvora según las indicaciones de Pérez de Anticona, sería posible perforar en el mismo plazo más de trescientos metros, afirmación completamente fuera de lugar por ser muy optimista.

Mientras tanto, el 5 de febrero de 1632 el virrey nombró gobernador a Gregorio Arce de Sevilla, relator de la Audiencia de Lima, en sustitución de Juan de la Celda debido a su quebrantada salud. Siguiendo instrucciones del conde de Chinchón, Arce dedicó sus esfuerzos a acelerar el avance del socavón. 
Sin embargo, pasado un tiempo se comprobó que las vibraciones producidas por las explosiones y transmitidas por la roca, dañaban las paredes y apoyos de los huecos y galerías, ya de por sí poco resistentes. En conclusión, fue preciso volver al sistema antiguo, utilizando picos y no barretas, pues los golpes con éstas también ocasionaban dañinas vibraciones. Posiblemente la incidencia del arranque con pólvora en el socavón no fue demasiado significativa habida cuenta del reducido periodo de tiempo en que fue empleada, pero no se tienen noticias al respecto (Lohmann, 1949; Sánchez, 1997). Se ignora también cómo se evacuaban los gases de las explosiones y si, para ventilar, se construyeron respiraderos en el techo del socavón. La debilidad estructural de la mina, creada artificialmente por una mala praxis, cercenó la posibilidad de proseguir con el arranque mediante pólvora pero, no obstante, se había conseguido un hito: emplear por primera vez explosivos en una mina subterránea en América y, posiblemente, antes que en España. Desde luego, mucho antes que el Almadén.

El virrey, para mejorar el avance del socavón, decidió cambiar radicalmente la organización del trabajo. Si hasta entonces la obra se había efectuado según el libre criterio de los sucesivos gobernadores, que aplicaban a ella un número competente de obreros o la paralizaban durante un período más o menos largo, a partir de entonces la excavación se encargaría a un contratista que actuaría sometido a avances y plazos comprometidos. En noviembre de 1633 el experto veedor Antonio de Salvatierra había sugerido al virrey dicha fórmula, considerando que era más ventajosa para la salud de los obreros. Salvatierra propuso que la obra del socavón se encargara a Constantino de Vasconcelos, a la sazón residente en Oruro, a quien tanto él como el ex gobernador Sigoney y Luján conocían por haber realizado con rapidez obras de mucha consideración. Sin embargo, la oportunidad de que Vasconcelos trabajase en la mina tardaría aun casi diez años en llegar: sería después de concluirse el socavón.

El asiento con los mineros que estaba vigente caducó el 1 de julio de 1633 pero se prorrogó en plazos anuales hasta 1645, año en que se formalizó otro nuevo. El gobernador Arce de Sevilla, atajando corruptelas, fue obteniendo las producciones de azogue comprometidas. Al cabo de un año y medio de continuos sinsabores, en septiembre de 1633 , se retiró a descansar a la provincia de Angaraes, en donde fue envenenado. El 8 de noviembre, el virrey nombró como sustituto al alcalde del crimen Fernando de Saavedra. Con él, la minería huancavelicana del mercurio volvió a su antiguo esplendor, aunque solo durante un breve espacio de tiempo, produciendo una media anual de 5.000 quintales de azogue (Lohmann, 1949).
En este contexto, en 1635 se llevó a la práctica la idea de 1633 de encargar la obra del socavón Nuestra Señora de Belén a un privado: por mandato del virrey, el gobernador Saavedra contrató al cantero Juan de Bielsa, en aquel entonces maestro mayor en las minas, para que procediese a la excavación de la galería, trabajando a destajo, con el compromiso de concluirla en diez años. Bielsa recibiría una prima por cada año que acortase la obra, de la que aún faltaban, después de veintinueve años de labor, los dos tercios de la longitud prevista; por su parte, los mineros ofrecieron dar 20.000 quintales de azogue si en el término enunciado se dejaba practicable dicho túnel. La traza del socavón fue ligeramente modificada por el ya citado Francisco de Quirós, cosmógrafo mayor del virreinato, pero Bielsa, bajo su responsabilidad, resolvió desviar la orientación una cuarta al haber comprobado que, si se hubiera seguido el diseño de Quirós, el socavón habría cortado a la mina $50 \mathrm{~m}$ más arriba del lugar conveniente. Las ventajas de la reestructuración laboral del virrey se evidenciaron rápidamente pues, en el mismo año de 1635, Bielsa perforó más de $40 \mathrm{~m}$, cuando lo convenido era un promedio de $30 \mathrm{~m}$ al año.

El gobernador Fernando de Saavedra cesó en marzo de 1636 a causa de su mala salud. En su lugar, un año después, en abril de 1637, el virrey nombró a Juan de la Cerda, antiguo corregidor de Porco.

En estos años tuvo lugar un hecho importantísimo, de grandes consecuencias en el beneficio del mercurio de Huancavelica y Almadén, que fue el descubrimiento de los hornos de aludeles por Lope de Saavedra Barba. Dichos hornos serían empleados, con mejoras, hasta el primer cuarto del siglo XX y su historia bien merece un breve comentario. Saavedra inició sus experimentos en 1629 buscando mejorar el rendimiento del horno de jabecas, usado en esos momentos. Tras cuatro años de ensayos, el 14 de noviembre de 1633 presentó al conde de Chinchón un memorial explicando su invento, el horno de aludeles, solicitando varios peones para repetir los experimentos a mayor escala. El virrey aceptó llevándose a cabo la prueba en Lima en septiembre de 1635 en presencia del gobernador Fernando de Saavedra y del propio virrey. Los resultados fueron un éxito, mejorando sensiblemente los rendimientos obtenidos hasta ese momento por los hornos de jabecas. Tras introducir diversas mejoras, la prueba definitiva tuvo lugar en octubre de 1637, pero algunos mineros ya habían comenzado a comprobar la bonanza del nuevo horno. Los magníficos resultados conseguidos condujeron a que en la campaña 1637-1638 bastantes mineros emplearan el nuevo horno, comenzando un rápido declive de los de jabecas (Lohmann, 1949).

Pese a los nuevos hornos diseñados por Saavedra, la disponibilidad de azogue en Perú sufrió notables al- 
tibajos entre 1636 y 1642 debido, sobre todo, a la irregular llegada de mercurio desde España pero también a la deficiente situación de las minas huancavelicanas (Lohmann, 1949).

Mientras tanto, la labor del socavón Nuestra Señora de Belén continuaba con la mayor diligencia. En carta al rey del 11 de mayo de 1639, el virrey informaba de los últimos cálculos de Quirós y de Bielsa, que coincidían en que la longitud previsible del socavón sería de 670 varas $(560 \mathrm{~m})$, de las cuales se rebajaron 40 por razón de los huecos de la mina con lo que, en realidad, serían 630 varas $(527 \mathrm{~m})$, de las que ya se habían perforado 530 (443 m). Por tanto, faltaban solamente 100 varas $(84 \mathrm{~m})$ para calar a la explotación (AGI. Lima, 45).

En su relación de gobierno, fechada el 26 de enero de 1640, el conde de Chinchón informaba a su sucesor de que entre 1606 y 1635 el socavón había avanzado 214 varas $(179 \mathrm{~m})$, mientras que entre este año y 1640 había ganado 326 varas ( 272 m). Comentaba, además, que desde hacía varios meses se estaba tan cerca de llegar a la mina que, dentro de ella, se oían los golpes de las barretas o picos (BNE. Ms. 3080, F. 28r).

\section{El virrey Pedro de Toledo y Leiva, marqués de Mance- ra, y la conclusión del socavón}

Este fue el panorama que encontró el nuevo virrey, Pedro de Toledo y Leyva, marqués de Mancera, cuando llegó a Lima el 18 de diciembre de 1639. El hecho de que llevara consigo 4.000 quintales de azogue que se unieron a los 24.000 que dejó de reserva el conde de Chinchón le permitieron un cierto desahogo durante dos años.

En relación con el nuevo tratamiento metalúrgico de Saavedra cabe señalar que en 1640, los 60 hornos diseminados al pie del cerro eran de aludeles, en cada uno de los cuales se trataban de 100 a 300 quintales de mineral. Saavedra luchó por sus derechos de patente que, tras muchos esfuerzos, le fueron concedidos con la oposición de los mineros, que querían disfrutar gratis del novedoso y productivo diseño. Por fin el 14 de agosto de 1641 una provisión concedió a Saavedra durante su vida y otra más para sus herederos, una cantidad equivalente al valor del $2 \%$ libre de todo el azogue que de cualquier manera se beneficiara en Huancavelica. El inventor, que falleció el 24 de marzo de 1645, y sus descendientes padecieron un calvario para cobrar estas cantidades tanto por parte de la Hacienda Real como de los mineros, cuyas cuotas ascendían aproximada y respectivamente a 1.500 y 5.900 pesos al año, por cierto, cantidades nada generosas comparadas con la enorme aportación que el método de Saavedra había proporcionado a ambos. Por el contrario, un sujeto Ilamado Juan Alonso de Bustamante, enterado del procedimiento, lo llevó a Almadén en 1646, mejorándolo; por ello fue colmado de galardones en el Perú. Incluso el horno pasó a denominarse en España de Bustamante, hecho absolutamente injusto con Saavedra (Lohmann, 1949).

En mayo de 1639, a causa de haberse adelgazado los pilares de sostenimiento de las labores, ocurrieron diversos derrumbes que continuarían hasta mediados del siguiente año. En diciembre del citado 1639, gobernando todavía el conde de Chinchón, un nuevo derrumbe ocasionó varios muertos, afectando al único tajo que proporcionaba mineral de cierta calidad, el cual quedó enterrado. El 28 de junio de 1640, cuando todavía estaban realizándose las reparaciones, un nuevo derrumbe, igualmente ocasionado por el descalce de los pilares, obstruyó el lugar por el que se proporcionaba ventilación a todas las galerías, lo que tuvo como consecuencia inmediata impedir el paso a éstas y aparejar una drástica reducción de la cantidad de mercurio producido. Puesto que la boca de entrada a las minas quedó obstruida y aún no estaba finalizado el socavón de Nuestra Señora de Belén, no podía ingresarse a las explotaciones. Como alternativa para paliar la situación, se reexplotaron algunas zonas pobres a cielo abierto cuyos minerales no pudieron ser tratados en su día con los antiguos hornos de jabecas pero ahora si podían ser beneficiados en los nuevos diseñados por Saavedra. En resumen, volvieron a repetirse los mismos problemas que afrontara el conde de Chinchón al comienzo de su mandato. En los años 1640 y 1641 la producción de azogue fue de unos 2.500 quintales anuales, la mitad del cupo asignado en el asiento de 1630.

Para averiguar las causas de los derrumbes, el marqués de Mancera había nombrado en febrero de 1640 a Juan Fermín de Izu visitador encargado de investigar la situación en Huancavelica. Sus pesquisas finalizaron en cinco meses, tras los cuales se sometió a juicio al gobernador Juan de la Cerda así como a sus subordinados, por no haber actuado con diligencia cuando ocurrieron los primeros desmoronamientos en las galerías. De la Cerda fue condenado a una multa de 10.000 pesos y destierro de 10 años de la villa. En la misma proporción fueron sancionados los funcionarios que habían estado a sus órdenes. Para llevar a cabo sus pesquisas, el visitador Izu quiso recorrer las minas para proceder luego a su restauración pero fue imposible acceder a las zonas productivas por estar ocupadas por gases letales que, incluso, ocasionaron la muerte de varios de sus acompañantes que decidieron penetrar en ellas. Lo que si apreció Izu es que los reparos que era necesario acometer para 
poner en marcha las minas eran de tal envergadura que sólo la Hacienda Real podría costearlos. Mientras tanto, como la explotación normal de las vetas era imposible, los esfuerzos se centraron en sacar mineral de zonas marginales explotadas previamente (muros, pilares y bóvedas de partes accesibles de la mina) que, según el asiento vigente, eran propiedad de la Corona. Para ello, se firmó un acuerdo entre el virrey y los mineros de modo que éstos pudieran beneficiarlos. El encargado de vigilar que estas explotaciones se realizaran correctamente fue el nuevo gobernador, Rodrigo de Mendoza, que sustituyó a Izu. Cuando en julio de 1640 tomó posesión de su cargo, la situación era muy difícil. Sin embargo, Mendoza supo motivar a los mineros para que llevaran adelante el acuerdo y así lo hicieron obteniendo en 1641 la producción comprometida en él (Lohmann, 1949). Mientras tanto, un desesperado virrey intentaba facilitar que se llegase a las labores hundidas haciendo reparaciones y promoviendo la búsqueda de huecos entre las ruinas aunque era consciente de que llegar a las labores ricas implicaba un trabajo inmenso y que, llegados a ellas, aunque se podría sacar mucha cantidad de mercurio sería a un coste muy elevado por la falta de ventilación y la consiguiente mortalidad de los indios (AGI. Lima, 51).

Coetáneamente con el desarrollo de los hechos relatados, en una situación de congoja general ocasionada por la falta de acceso a la mina, se redoblaron los esfuerzos para avanzar el socavón con la mayor rapidez posible. A tal efecto, el contratista de la obra, Juan de Bielsa, había recibido órdenes apremiantes del virrey alentándole con la promesa de recompensarle adecuadamente si terminaba la obra en breve plazo.

Según el marqués de Mancera, simultáneamente con el socavón Nuestra Señora de Belén se estaba perforando otro que se comprobó iba errado en más de 60 varas de manera que no llegaría a cortar los huecos de la mina. El virrey ordenó paralizar esta obra y concentrar los esfuerzos en la principal ensanchando dos brazas los frontones para mejorar la ventilación que ya faltaba. Con ello se pudieron añadir al trabajo un número doble de obreros (AGI. Lima, 51).

Finalmente, al cabo de treinta y seis años de esfuerzos y problemas, y habiendo reconocido una vetilla de mineral, el socavón caló las labores de la mina en la medianoche del Lunes Santo 14 abril de 1642 abriéndose un portillo de comunicación (Lohmann, 1949).

Durante las primeras horas de la madrugada se ensanchó el boquete, lo que permitió ventilar las labores subterráneas. Al respecto, decía el virrey que por el portillo entraba tanto aire a la mina que ya no había peligro para nadie por mala ventilación (AGI. Lima, 51).
El hueco abierto estaba situado a $8,5 \mathrm{~m}$ por encima del piso de las labores, exactamente en el lugar calculado. Bielsa, adoptando las debidas precauciones ante la posible presencia de gases venenosos, descendió mediante una escalera de mano el citado desnivel hasta alcanzar el suelo de la galería. Como por el hueco de comunicación soplaba una fuerte corriente de aire, Bielsa tuvo que cubrir con su capa el velón que portaba para iluminarse. El lugar donde se produjo la comunicación era aquel en que dos años antes habían perdido la vida diversas personas que acompañaban al visitador Izu envenenadas por los gases.

La longitud total del socavón era de 672 varas (562 $\mathrm{m})$, de los cuales 143 varas (102 m) se habían avanzado en época de Mancera. Recuérdese que Quiroa y Bielsa, en 1639, evaluaron la longitud en 630 varas. Cerca de la boca, el socavón medía $3 \times 3 \mathrm{~m}$, aunque luego se estrechaba ligeramente. La competencia de Bielsa para esta clase de obras quedó plenamente acreditada, pese a que no le fue fácil desarrollar su trabajo debido a las intromisiones del gobernador De la Cerda, que le obligó a tomar otra dirección, por creer que la que se seguía iba errada y no se desembocaría en la zona rica del yacimiento. Cuando el gobernador cesó en el cargo, Bielsa volvió a la orientación primitiva, respaldada por los cálculos del cosmógrafo Quirós, realizados con tal precisión que, a una distancia de $400 \mathrm{~m}$ aproximadamente, acertó en el punto fijado. Terminada la perforación, el virrey ordenó que Quirós reconociera el socavón, a fin de que dictaminara sobre su solidez (Lohmann, 1949).

Al día siguiente el gobernador y los funcionarios de la Hacienda Real descendieron a los lugares de la mina que habían permanecido inaccesibles desde hacía tres años. Sin el menor sobresalto, en una atmósfera limpia, reconocieron los frontones, que poco después comenzaron otra vez a explotarse, con general satisfacción de los mineros. En la bocamina del socavón se construyó una portada, en cuyo tímpano se colocaron las armas reales; más abajo y a ambos lados, las del marqués de Mancera y las de la villa de Huancavelica.

Las hasta entonces inaccesibles labores ya no lo serían y el socavón saneaba su atmósfera justo cuando más falta hacía. El reciente contrato para explotar zonas marginales se suspendió de inmediato procediéndose a preparar la comunicación entre la mina y el socavón y a acopiar el mineral que quedaba en las galerías desmoronadas (Lohmann, 1949).

La finalización del socavón fue un gran acontecimiento en Huancavelica. La mina se hallaba tan fresca, el camino para las labores principales estaba tan expedito y la comunicación era tan fácil por el socavón que muchos españoles e indios entraron en la mina y 
celebraron este suceso con bailes, músicas y fiestas. En palabras del marqués de Mancera, la mina había pasado de ser un horror debido a las vidas que allí se habían perdido a convertirse en sitio placentero (AGI. Lima, 51).

En Lima también se celebró la conclusión de la obra. El Sábado de Gloria, 20 de abril de 1642, se conoció la noticia. Aquella misma tarde hubo grandes fiestas, candelas, luminarias y carreras de todos los cabaIleros y del general del Callao, hijo del virrey marqués de Mancera. Por la noche salieron muchas personas nobles vestidas de colores y con plumas blancas, entre ellas el virrey y su hijo, todas los cuales anduvieron por las calles celebrando la finalización del socavón y el éxito en el acertado cale a las labores (Mugaburu and Mugaburu, 1917).

Sin embargo, la obra del socavón no había sido nada fácil de realizar pues el diseño original de Pedro Ozores de Ulloa y la primera corrección hecha por Francisco de Quirós presentaban errores que habrían dado al traste con el objetivo perseguido pues la galería no habría cortado las labores. A este respecto, un visitador oficial de la mina que reconoció el socavón a los pocos años de terminarse, explicó que cuando Quirós dispuso la traza del socavón, lo encaminó 60 varas más arriba de donde terminó, pero Juan de Bielsa torció una cuarta de rumbo para llevarlo más abajo otras 60 varas, y si no se hubiera hecho esta corrección, la galería habría pasado por encima de las labores subterráneas (AGI. Lima, 52).

Y si la obra no fue fácil, tampoco salió barata a los mineros, que tuvieron que pagar por ella, según Solórzano, más de un millón de pesos (Rivero, 1857).

\section{La apertura del socavón}

Con la apertura del socavón se recobraron las esperanzas perdidas. La extracción del mineral se facilitó en gran manera pues la sacada al exterior se efectuaba por terreno llano, aunque los recorridos por el interior de la mina a los distintos frontones se seguían efectuando superando los desniveles mediante escaleras. La última dificultad era salvar los $8,5 \mathrm{~m}$ de diferencia entre el nivel de la boca del socavón y el piso de la galería a la que cortaba, para lo cual se construyó una escalera de madera muy inclinada, con callapos atados mediante unas cuerdas elaboradas con icho (AGI. Lima, 52).

Antes de que entrara en funcionamiento el socavón, el mineral tenía que ser llevado por los apiris o cargadores hasta la bocamina desde una profundidad de $200 \mathrm{~m}$ por galerías tortuosas y escarpadas ascendiendo mediante 31 escalas un total de 503 peldaños, asidos con una mano, mientras que con la otra sostenían la carga. En estas condiciones, cada apiri hacía un viaje diario; sin embargo, con la apertura del socavón se aumentaron a casi cuarenta por jornada. Lo mismo puede decirse de la extracción de los escombros acumulados en el interior de las galerías hasta la bocamina del socavón. Además, la galería permitía establecer una corriente de aire que mantenía muy frescas las labores subterráneas, de manera que desapareció la fuerte diferencia de temperatura entre el ambiente y el interior del cerro que tan nociva era para los obreros cuando salían al exterior sudorosos y se exponían a la fría temperatura de la sierra. Además, en lo sucesivo, nadie corrió peligro de sofocarse con el polvo, los olores y los humos causados por el laboreo. Con estas mejoras, la extracción tendría costes mucho más pequeños pues cada obrero no sólo podría realizar mayor número de viajes a través del socavón, sino que se volvía a explotar mineral de alta ley (Lohmann, 1949). Sin embargo, el deseado socavón que tantos beneficios iba a producir, indujo la preocupación entre los mineros, pues, con el abaratamiento de los costes y la abundancia de mercurio, el precio del metal bajaría (Sala, 1994).

Concluido el socavón Nuestra Señora de Belén, el marqués de Mancera decidió que se estudiara el mejor plan de explotación de la mina para lo cual, en abril de 1643, nombro gobernador de Huancavelica al oidor Martín de Arriola Valerdi. Su misión sería reconocer el estado de los trabajos, subsanar los daños emergentes y realizar una inspección de las actividades de los funcionarios de la Hacienda Real. Le acompañaría Constantino de Vasconcelos, portugués, persona muy entendida en materias de minería, con experiencia en Oruro y Potosí. El virrey concedió a ambos plenos poderes para establecer el futuro método de explotación hasta el punto de que prohibió que se iniciase cualquier trabajo minero sin su aprobación. Vasconcelos recorrió la mina y elaboró un plano de las labores situadas al final del socavón recién terminado que, acompañado de una memoria, remitió al virrey el 16 de octubre de 1643 (Figura 4). Es el primer plano que incluye el socavón, aunque solamente su extremo final.

En él puede verse la ubicación de la citada galería de acceso $(\mathrm{V}, \mathrm{Y})$ así como la escalera que se construyó para bajar a las labores caladas (F-D), con un desnivel de 8,5 $m$. Se aprecian, igualmente, una zona derrumbada (A), los estribos $(G, H, I)$, la gran oquedad de Hojaldrado (T), el tajo de Hoyo Negro (L, M, N) e, incluso, un bojeado (U) o cale pequeño entre dos labores superpuestas en vertical, en este caso Hojaldrado y una galería a nivel inferior que deriva del Cañón señalado con una O. 


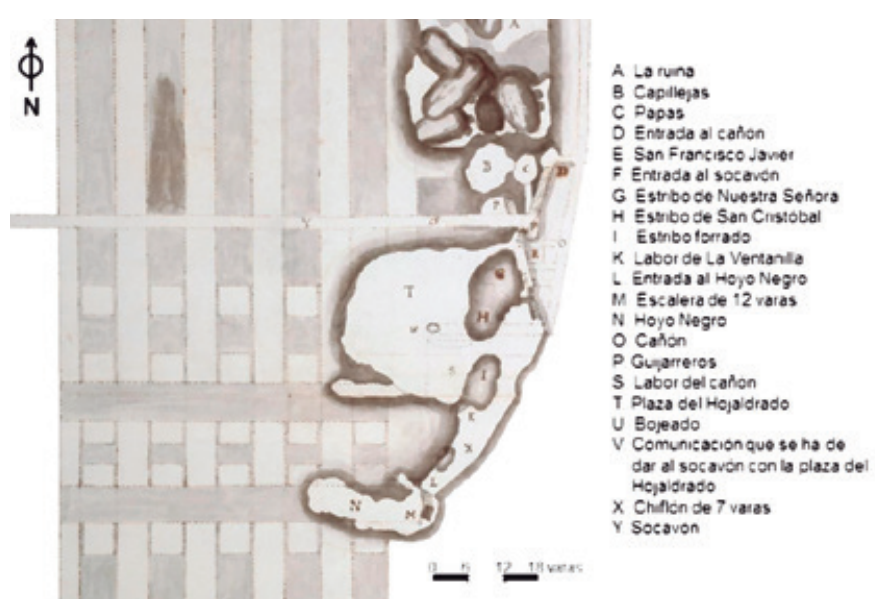

Figura 4. Plano de Vasconcelos (Fuente: AGI. Lima, 51, Lám. VIII, en Feraud y Wise, 2006, modificada).

Figure 4: Plan of Vasconcelos (Source: AGI. Lima, 51, Plate VIII, in Feraud and Wise, 2006, modified).

\section{Geología del distrito de Santa Bárbara y del socavón}

Como es de suponer los documentos coloniales apenas proporcionan información sobre la geología de Santa Bárbara. Ya en época republicana, en 1850 y 1851, León Crosnier fue contratado por el gobierno para que realizara una exploración mineralógica por los departamentos de Huancavelica y Ayacucho (Crosnier, 1852). Durante su visita a Santa Bárbara penetró en la mina cuatro días, por el socavón, dejando la primera descripción de las rocas atravesadas por él, que fue la siguiente, desde la bocamina hacia el interior:

- Brechas y pudingas con cantos y cemento calcáreo atravesados por vetas de calcita. Más de $100 \mathrm{~m}$ de potencia.

- Alternancia de calizas compacta y arcillas.

- Conglomerados y pudingas con cantos de arenisca y de caliza mezclados, unidos por cemento calcáreo y atravesados por vetillas de espato calizo.

- Caliza compacta negruzca con vetillas de calcita cristalizada.

- Arcilla parda endurecida.

- Areniscas silíceas.

- Potentes capas de arcilla endurecida.

Poco después, hacia 1857, Mariano E. Rivero, visitó la mina penetrando por el socavón, del que apuntó que estaba perforado con dirección E-O, en el conglomerado formado por cantos calcáreos azules de diferentes tamaños, en la caliza y en la arenisca, alternando estas capas con más o menos potencia.

El primer intento real de describir la geología del distrito se debe a A.F. Umlauff que, en 1904 emitió un informe para el Negociado de Minas del Perú en el incluía un mapa geológico muy simple y una descripción de las principales formaciones. Otros autores posteriormente describieron el distrito sin añadir planos ni detalles sobre el socavón (Berry and Singewald, 1922). Cuando la mina de Santa Bárbara comenzó a ser reexplotada en 1917 por el empresario Eulogio F. Fernandini, el socavón estaba hundido a los $228 \mathrm{~m}$ de la bocamina. Sin embargo, fue recuperado en su totalidad por el ingeniero Ambrosio Gastelumendi que dejó testimonio de la presencia de gruesas capas de arcilla con intercalaciones de conglomerados, calizas y una intrusión de pórfido descompuesto. Tras medir la galería comprobó que tenía $508 \mathrm{~m}$ de longitud, un desnivel entre sus extremos de 5,51 m, con una pendiente de $1,08 \%$. El socavón tenía un rumbo de $\mathrm{N}-60^{\circ}-\mathrm{E}$ presentando un codo de $170^{\circ} 30^{\prime}$ a los $105 \mathrm{~m}$ de su boca, siguiendo en adelante la dirección N-69 $30^{\circ}$ '-E (Gastelumendi, 1920).

En lo relativo a datar las formaciones de Santa Bárbara, Enrique I. Dueñas, en 1908, fue el primer autor que refiere la presencia de fósiles en ellas, pero no fue hasta 1922 que Berry y Singlewald estudiaron con más profundidad el asunto tras encontrar calizas con abundante fauna de pelecípodos, gasterópodos y equinodermos que dataron de edad Aptiense, Albiense, Cenomaniense y Emscheriense, término obsoleto de Coniaciense y Santoniense (Berry and Singewald, 1922).

Para encontrar información geológica de mayor detalle y fiabilidad hay que esperar a la investigación de Yates et al (1951) realizada por el Servicio Geológico de EE.UU y el recién creado Instituto Geológico del Perú, dentro del programa de cooperación entre los dos países. Los trabajos de campo se efectuaron desde agosto hasta diciembre de 1945 y, durante ellos, se estudió la geología del distrito y se realizó el levantamiento geológico del socavón en los $380 \mathrm{~m}$ iniciales ya que el resto estaba hundido de nuevo.

La descripción geológica de las formaciones que fueron cortadas por el socavón son las siguientes, de más antigua a más reciente:

- Grupo Goyllarisquizga. Conocido también como Arenisca Gran Farallón. Se compone de arenisca gris claro a blanca, de grano fino a grueso, unidos por cemento silíceo cuyo grado de descomposición es variable lo que proporciona consistencias desde friables a casi cuarcíticas. Presenta escasas intercalaciones de pizarra, que son más frecuentes en la parte inferior. No pudo medirse la potencia, que fue estimada en 500 $\mathrm{m}$. Se han encontrado restos inclasificables de vegetales. Por criterios estratigráficos se le ha asignado una edad Cretácico inferior. Esta es la formación que presenta un mayor grado de mineralización diseminada en el intergranulary las fracturas.

- Volcánico Chayllacatana. Concordante con la anterior, se compone de lavas de carácter básico y pizarras 
tobáceas con escasas intercalaciones de conglomerados y calizas. Son de color rojo o rojo verdoso y se descomponen con facilidad por la meteorización. Son azoicas. La potencia estimada es de $500 \mathrm{~m}$.

- Caliza Machay. Formada por calizas de color blanco a gris, de grano fino, estratificación mediana, con intercalaciones de caliza margosa y pizarra roja. Es concordante con la anterior. La potencia estimada es de $600 \mathrm{~m}$. Contiene fósiles diagnósticos de edad cretácica. Aquí encontraron Berry y Singlewald los fósiles a los que ya se ha hecho referencia que, reinterpretados, se asignaron al Aptiense-Albiense inferior y medio.

- Formación Casapalca. Se presenta discordante sobre las formaciones cretácicas. Está compuesta por conglomerados y pizarras tobáceas interestratificadas. Los cantos son heterométricos $(1 \mathrm{~cm}$ a $1 \mathrm{~m})$, redondeados y subangulares, de caliza, cementados en una matriz de arena y pizarra. Contiene nódulos de sílex. La potencia estimada es de $120 \mathrm{~m}$. Es azoica. Se la asigna probable edad Terciario inferior.

Basándose en estas descripciones, Yates et al. (1951) realizaron el levantamiento geológico del socavón en sus $380 \mathrm{~m}$ iniciales. La Figura 5 muestra el citado perfil con indicación de los avances conseguidos en los distintos años, según la escasa información aportada por la documentación de la época. Además, tomando como referencia estos mismos datos, la Figura 6 muestra la distancia perforada acumulada desde su inicio (1606) hasta la conclusión (1642). Igualmente, a partir de dicha información se han calculado los avances medios anuales por periodos de tiempo que se indican en la Figura 7. Para interpretar las dificultades habidas durante la perforación de la galería, deben considerarse las tres conjuntamente. Todas ellas ponen de relieve claramente los hechos que se han comentado en el texto, es decir, la lenta marcha en los años iniciales, la paralización de la obra entre septiembre de 1608 y octubre de 1617, los escasos rendimientos obtenidos tras la reanudación de los trabajos y el fuerte impulso experimentado a partir de 1635 , año en que el socavón se realizó mediante la contratación de la obra a un privado.

El emboquille se efectuó en la Formación Casapalca, concretamente en conglomerados compactos con buzamiento aparente en la dirección de la galería de $35^{\circ}-40^{\circ}$ y sentido contrario al avance del socavón. Pese a que se eligió conscientemente una roca compacta para abrir el portal, los bancos conglomeráticos opusieron serios problemas para el avance, como muestran las citadas figuras. A los $46 \mathrm{~m}$ encontraron una fractura que, con toda probabilidad, estuvo relacionada con las dificultades de la excavación que concluyeron en la parada de la obra en 1608. Retomada en 1617 se avanzó hasta los 86 m aproximadamente, en donde se entró en las calizas de la Formación Machay tras atravesar el contacto con discordancia angular. Esta formación tiene una inclinación aparente de $50^{\circ}$ en sentido contrario al avance del socavón, bastante uniforme durante los $194 \mathrm{~m}$ que se perforaron en ella. Las calizas presentan numerosas fracturas que, junto con problemas de otra índole comentados en el texto, ralentizaron sensiblemente el avance entre 1623 y 1634 (Figura 7). El cambio de régimen laboral habido en 1635 trajo consigo un aumento espectacular de la velocidad de excavación que, aparentemente, atravesó sin problemas la mitad inferior de la Formación Machay. Tras pasar una fractura, el socavón entró en el complejo volcánico y pizarroso de la Formación ChayIlacatana. Estos materiales no debieron oponer demasiada resistencia al avance aunque el paso por las zonas blandas hubo de entibarse, al menos en algunos pasajes con una estructura en tijera. Por estos materiales se avanzaron $100 \mathrm{~m}$ hasta encontrar el derrumbe que interrumpía el paso a los $380 \mathrm{~m}$ de la bocamina. Se desconoce el material existente en el resto de la galería que, mayoritariamente, debió discurrir por la Formación Chayllacatana hasta que encontró las areniscas del Grupo Goyllarisquizga, roca de caja de la mineralización explotada en la mina. Posiblemente el descenso del rendimiento de los años finales se debió, entre otras posibles causas, a que el socavón cortase las duras areniscas del Gran Farallón (Figura 7).

En lo relativo a la facilidad de excavación, el perfil muestra que la estratificación general era muy desfavorable para el arranque ya que las capas están inclinadas en dirección contraria al avance. Con esta configuración geológica no pudo aprovecharse la debilidad que ofrecían los planos de estratificación para introducir cuñas por ellos y apalancar para hacer saltar grandes fragmentos de roca; por el contrario, tuvieron que perforarla enfrentándose a su dureza en condiciones muy desfavorables. Cuando la roca era blanda, no habría problema pero en el caso de roca dura, el avance sería más lento y problemático. La pólvora se empleó a partir de 1631 durante un corto periodo de tiempo ya que las vibraciones desestabilizaban las paredes de la galería. Su uso parece que no ocasionó grandes avances, según muestra la Figura 7.

El socavón no cortó veta alguna salvo una pequeña al final del mismo.

Con posterioridad a las investigaciones geológicas referidas, la Carta Geológica Nacional a E:1/100.000 de 1996 matizó algunos conceptos de Yates et al. (1951), estableciendo precisiones dentro de cada formación y revisando su datación (Morche and Larico, 1996).

Así, reduce la potencia del Grupo Goyllarisquizga a 200 m y comprueba que la formación Gran Farallón es el miembro medio del grupo, intercalado entre uno 


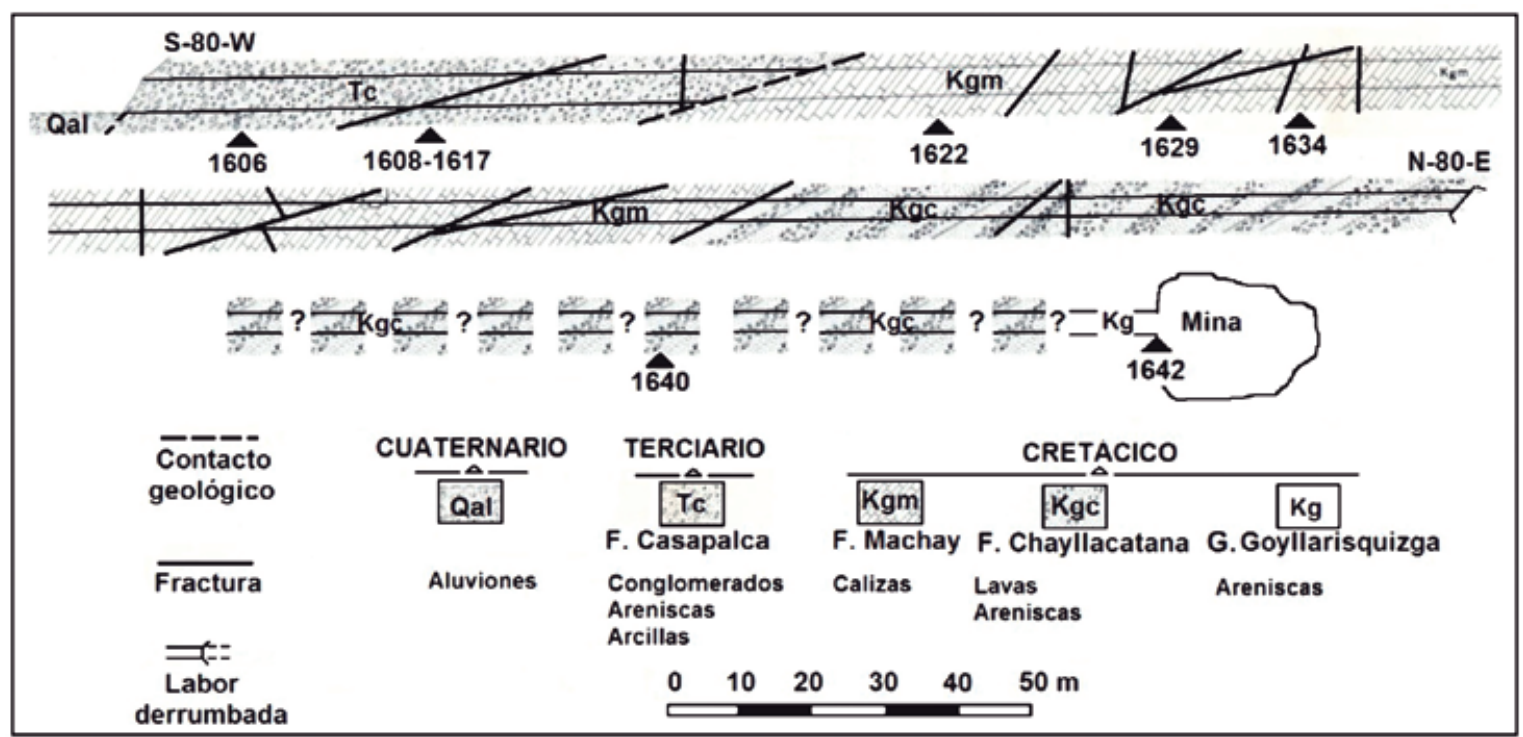

Figura 5. Perfil geológico de los $380 \mathrm{~m}$ iniciales del socavón y avances (Fuente: Autores basado en Yates et al., 1951).

Figure 5. Geological profile of the initial $380 \mathrm{~m}$ of the adit and advances (Source: Authors based on Yates et al., 1951).

inferior formado por areniscas con intercalaciones de limoarcillitas, capitas de carbón y troncos fosilizados, y otro superior constituido por lutitas alternantes con areniscas, en cuyo techo se encuentran derrames lávicos diferenciados y cartografiados como Formación Chayllacatana por Yates et al. (1951). Los espacios intergranulares del miembro inferior albergan la principal mineralización de mercurio. La edad atribuida es Neocomiense (Berriasiense-Barremiense).

La Formación Chayllacatana ve reducida su potencia hasta los $200 \mathrm{~m}$. Además, se le atribuye edad Neocomiense superior.

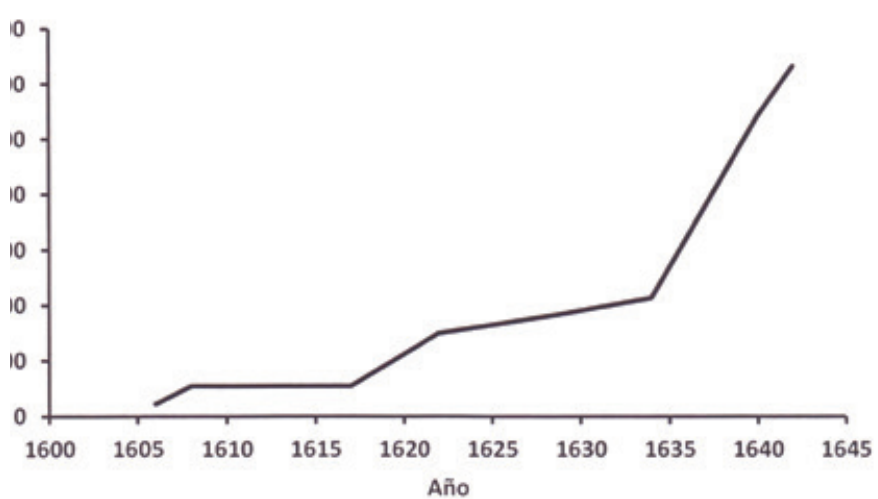

Figura 6. Avance acumulado del socavón (Fuente: Autores). Figure 6. Cumulative progress of the adit (Source: Authors).
Se establece en el distrito una nueva formación, denominada Chúlec, descrita en la región central de Perú, que corresponde al miembro inferior de la Caliza Machay. Está compuesta por micritas gris claro con nódulos de chert y margas calcáreas fosilíferas. Basándose en criterios estratigráficos y paleontológicos, la edad que se le atribuye es Albiense medio.

Finalmente, amplia la descripción de la Formación Casapalca que se compone de lutitas rojas con intercalaciones de conglomerado y areniscas rojas, y algunos yesos, arcillas y carbonatos que, en conjunto, son representativos de la erosión ocurrida a finales del

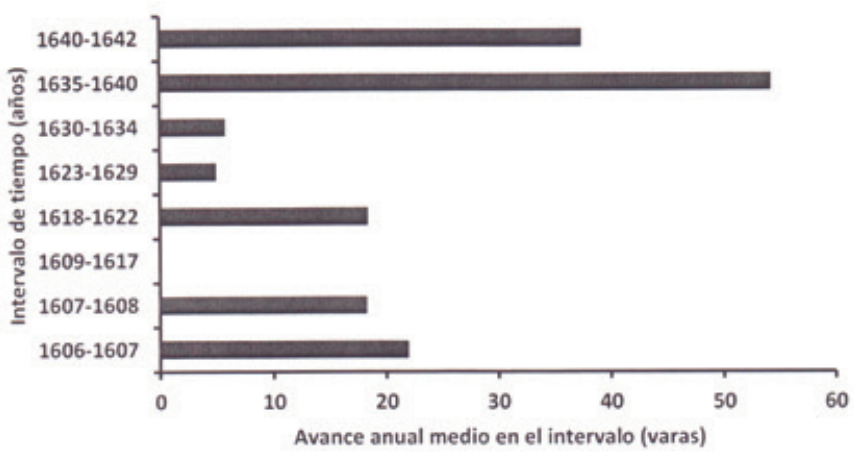

Figura 7. Avances medios anuales del socavón por períodos de tiempo (Fuente: Autores).

Figure 7. Average annual progress of the adit by time periods(Source: Authors). 
Cretácico. La potencia se amplía a $200 \mathrm{~m}$. Por consideraciones estratigráficas y tectónicas, se le asigna edad Santoniense-Paleoceno.

La última cartografía geológica publicada, a $E: 1 / 25.000$, se debe a Wise (2000). Empleando información de la Compañía Minera El Brocal, S.A.A., concesionaria de Santa Bárbara, en lo que respecta al socavón concluye que la Formación Casapalca es más joven de lo previsto, considerándola el conglomerado de base del Mioceno.

\section{Conclusiones}

La mina de azogue de Huancavelica fue segunda más importante del virreinato del Perú, detrás de Potosí. Las labores mineras se realizaron, inicialmente, a cielo abierto aunque pronto profundizaron y fue preciso cambiar al método de explotación subterránea. Sin embargo, la mala planificación y ejecución de los trabajos condujo a la mina a situaciones límite que se pretendieron atajar por varios métodos, entre ellos, la construcción de un larguísimo socavón (para la época). La obra se inició en 1606 y concluyó en 1642.

El inicio del socavón fue problemático pues hubo opiniones a favor de realizar otro tipo de obras, como un gran desmonte y unas lumbreras pero, dado el estado de necesidad de la mina, se optó por iniciarlas todas sin saber bien cuál y cómo concluirían. Finalmente, se consideró que el socavón era la solución definitiva y todos apostaron por excavarlo hasta el final.

Para acelerar su avance, se introdujeron en él dos mejoras significativas: la primera, el uso de la pólvora como medio de arranque; la segunda, el cambio de organización laboral desde un modelo público a otro por contrata con plazos y costes establecidos y pactados de antemano. La primera mejora fue un hecho destacable por la novedad que supuso: se empleó, posiblemente, antes que en España y, desde luego, mucho antes que en las minas de Almadén. Sin embargo, su efecto fue limitado cuando se comprobaron los efectos dañinos de las vibraciones ocasionadas por el estallido de la pólvora en la estabilidad de la galería. La segunda fue mucho más efectiva, pues supuso lograr avances nunca antes conocidos, tal vez condicionados en alguna medida por haberse encontrado roca más blanda que al inicio de la obra. Cabe señalar que la construcción de la galería tuvo numerosos controles que obligaron, a veces, a modificar su rumbo e inclinación. Finalmente, pese a la penuria de los medios técnicos existentes en la época, el socavón caló la mina en el sitio previsto, lo que puede considerarse un éxito notable en una labor tan larga (622 varas, $520 \mathrm{~m}$, en lugar de las 753 varas, $629 \mathrm{~m}$, inicialmente previstas). Aunque no se ha podido documentar adecuadamente cómo resolvieron el problema de la ventilación, un único testimonio hace referencia a la construcción de un segundo socavón que se abandonó en la etapa final de la obra para dedicar todos los esfuerzos al principal. También hubo propuestas para abrir pequeñas galerías verticales de ventilación hasta la superficie pero nada concreto se conoce de ello. El hecho es que se pudo trabajar hasta concluir una obra tan larga con buenos avances, especialmente hacia el final.

Es de destacar la transcendencia del socavón pues su apertura ocurrió en un momento especialmente grave para la mina, prácticamente paralizada por derrumbes y por la consiguiente falta de ventilación. En este sentido, el socavón resultó fundamental para el saneamiento del ambiente, el acceso a zonas antiguas con mineral extraíble y la apertura de nuevos tajos derivando ramales desde él, de manera que puede afirmarse categóricamente que la obra fue de importancia capital no sólo en el momento de su conclusión sino a lo largo de la restante vida de la mina. Sin el socavón de Nuestra Señora de Belén, posiblemente, las minas habrían cerrado con todo lo que ello pudo suponer en aquella época. La apertura del socavón implicó facilitar la extracción del mineral al exterior, mejorar las condiciones ambientales interiores y aumentar la seguridad al facilitar la evacuación de los heridos. Además permitió que los asentistas pudieran recortar gastos de transporte y mejoraran sus economías.

Durante las obras, la bocamina del socavón de Nuestra Señora de Belén, fue un centro de actividad importante y esta importancia se acrecentó con el tiempo, una vez abierta la galería, pues la mayor parte de la circulación de personas y mercancías a y desde la mina discurría por el socavón. Allí se reunían vendedores y obreros, se construyeron almacenes de materiales y viviendas para los encargados de la obra e, incluso, una cárcel para alojar a presos que trabajaron en la mina para redimir sus penas. Indudablemente, toda esta actividad influyó en el desarrollo y mantenimiento del pueblo de Santa Bárbara y de su magnífica iglesia colonial. En lo relativo a la villa, la construcción de su admirable patrimonio eclesial, casi siempre costeado por los mineros, tampoco habría sido posible sin el concurso de los beneficios económicos derivados de la apertura del socavón como garante de la permanencia de la minería.

En conclusión, el socavón de Nuestra Señora de Belén fue una obra larga y costosa en la que se emplearon procedimientos innovadores. Los beneficios que indujo a lo largo de varios siglos fueron evidentes y permitieron que la mina tuviera una larga vida. 


\section{Fuentes}

Archivo General de Indias (AGI)

Contratación. 5792. L. 2.

Lima. 35, 45, 51, 52, 94.

México. 27. $\mathrm{N}^{\circ}$ 24. BI. 5.

MP-Perú_Chile. 4, 5.

Patronato. 229. R. 60.

Patronato. 239. R. 38, R. 41, R. 43. BI. 1, R. 43. BI. 5, R. 43. BI. 6, R. 43. BI. 8, R. 44. BI. 1. N 3-4, R. 44. BI. 3. N 1 , R. 46. BI. 2. $N^{\circ}$ 2, R. 46. BI. 3. $N^{\circ} 2-3$, R. 47, R. 48. BI. 1. $N^{\circ} 6$.

Biblioteca de la Universidad de Sevilla. Papeles del marqués de Risco (PMR)

Manuscrito 330/135. F. 55, 57-64.

Biblioteca Nacional de España (BNE)

Manuscrito 2969. F. 969.

Manuscrito 3041. F. 115r, 117r-117v, 123v, 135r, 147v-148r, $154 \mathrm{r}-154 \mathrm{v}, 157 \mathrm{v}, 167 \mathrm{r}, 175 \mathrm{r}-177 \mathrm{v}, 181 \mathrm{r}-184 \mathrm{r}, 185 \mathrm{r}-192 \mathrm{v}$, 273r, 281r, 403r-407v, 442r-445r, 466r, 493r-493v, $495 r-497 v, 500 v-501 r$.

Manuscrito 3080. F. 28r.

\section{Referencias}

Amaré, M.P. y Orche, E. 2019. Juan de Sotomayor. Minero del azogue del Perú. In Mansilla, L. and Mata, J.M. (eds.). El Patrimonio Geológico y Minero. Identidad y motor de desarrollo. Instituto Geológico y Minero de España, Madrid, 307-326.

Aponte, J. 1622. Memorial que trata de la reformación del Reino del Pirú. In Marqués de Miraflores and Salva, M. 1867. (eds.) Colección de Documentos Inéditos para la Historia de España, Madrid, LI, 521-562.

Berry, E.W.; Singewald, J.T. 1922. The geology and paleontology of the Huancavelica mercury district. The Johns Hopkins University Studies in Geology. The Johns Hopkins Press, Baltimore, 2, $101 \mathrm{pp}$.

Crosnier, L. 1852. Geologie du Perou. Notice geologique sur les departments de Huancavelica et d'Ayacucho. Annales de Mines, $5^{\text {a }}$ serie (2), 1-107.

Feraud, J. yWise, J.M. 2006. Los mapas históricos y el desarrollo de la mina Santa Bárbara, Huancavelica. ICOMOS. Congreso Internacional. El patrimonio minero e industrial: su incidencia e Importancia en los itinerarios culturales de relevancia universal. El caso de Almadén y otras explotaciones mineras vinculadas al Camino Real Intercontinental a través de la ruta del mercurio. Madrid-Almadén. Presentación.

Gastelumendi, A.G. 1920. Huancavelica como región productora de mercurio. In Anónimo (ed.), Congreso Nacional de la Industria Minera. Lima, 2, 39-64.
Hanke, L. 1978. Los virreyes españoles en América durante el gobierno de la Casa de Austria. Perú. Atlas, Madrid, 2, $284 \mathrm{pp}$.

Lohmann, G. 1949. Las minas de Huancavelica en los siglos XVI y XVII. Escuela de Estudios Hispano-Americanos. Sevilla, $465 \mathrm{pp}$.

López de Caravantes, F. 1987. Noticia General del Perú. Atlas, Madrid, III, 306 pp.

Mansilla, L.; Iraizoz, J.M. 2012. Aproximación al laboreo de minas y a la metalurgia en las minas de Almadén (Ciudad Real). De Re Metallica, 19, 79-93.

Morche, W. and Larico, W. 1996. Geología del cuadrángulo de Huancavelica. Hoja: 26- $n$. Boletín N 73. Serie A: Carta Geológica Nacional. Instituto Geológico Minero y Metalúrgico (INGEMMET), Lima, 172 pp.

Mugaburu, J. and Mugaburu, F. 1917. Diario de Lima (16401694). Crónica de la época colonial. Colección de libros y documentos referentes a la historia del Perú. Lima, VII.

Rivero, M.E. 1857. Memoria sobre la mina de azogue de Huancavelica. In Rivero, M.E. Colección de memorias científicas, agrícolas e industriales publicadas en distintas épocas. Bruselas, 2, 108-109.

Sala, J. 1994. Ciencia y Técnica en la Metropolización de América. Consejo Superior de Investigaciones Científicas, Madrid, $346 \mathrm{pp}$.

Sánchez, J. 1989. De minería, metalúrgica y comercio de metales. Ediciones Universidad de Salamanca/Instituto Geológico y Minero de España. Salamanca, 1, 415 pp.

Sánchez, J. 1997. La técnica en la producción de metales monedables en España y en América, 1500-1650. In Sánchez, J.; Mira, G.; Doblado, R. (eds.) La savia del Imperio. Tres estudios de economía colonial. Ediciones Universidad de Salamanca. Salamanca, 19-263.

Toledo, F. 1986. Disposiciones gubernativas para el virreinato del Perú. 1569-1574. Escuela de Estudios Hispano-Americanos/Monte de Piedad y Caja de Ahorros, Sevilla, $500 \mathrm{pp}$.

Wise, J.M. 2000. Geologic map of the Huancavelica Mercury District, Peru. 19/11/20, https://www.researchgate.net/ publication/303036112_Geologic_Map_of_the_Huancavelica_Mercury_District_Peru.

Yates, R. G.; Kent, D. F.; Fernández, J. 1951. Geology of the Huancavelica quicksilver district, Peru. U.S. Geological Survey Bulletin 975-A, Washington, 45 pp.

Zaldívar, M.I. 2016. Francisco de Borja y Aragón, príncipe de Esquilache. Relación y sentencia del virrey del Perú (1615-1621). Instituto de Estudios Auriseculares/Proyecto de Estudios Andinos, Nueva York, 270 pp.

Recibido: julio 2019

Revisado: noviembre 2019

Aceptado: enero 2020

Publicado: marzo 2021 